\title{
O histórico da rede urbana do Sul de Minas e a cidade média de Varginha
}

\author{
Sul de Minas urban network historical aspects and the middle-sized city of Varginha
}

\author{
Alexandre Carvalho de Andrade \\ Professor do IFSULDEMINAS/Poços de Caldas e do PPGEO UNIFAL-MG, Brasil \\ alexandre.andrade@,ifsuldeminas.edu.br \\ Rafaela Santos Costa de Figueiredo \\ Mestranda em Geografia (PPGEO UNIFAL-MG), Brasil \\ rafaela.figueiredo@sou.unifal-mg.edu.br \\ Rondinely Fernando Resende da Silva \\ Mestrando em Geografia (PPGEO UNIFAL-MG), Brasil \\ rondinely.silva@,sou.unifal-mg.edu.br
}

\begin{abstract}
Resumo
As cidades médias se caracterizam, dentre outras coisas, por suas posições intermediárias em uma rede urbana. Entretanto, com as dinâmicas econômicas, políticas, demográficas e socioculturais que incidem em um espaço geográfico, as redes urbanas se alteram, tanto com relação as posições hierárquicas de suas cidades, quanto pelas influências externas que nelas incidem. Este trabalho tem o objetivo de demonstrar os contextos históricos da rede urbana do Sul de Minas, com ênfase na posição da cidade média de Varginha. A referida região, localizada entre as importantes metrópoles de São Paulo, Rio de Janeiro e Belo Horizonte, apresenta efetivas relações com espaços externos, e deles recebe fortes influências por razões variadas, e, estas situações interferem nas dinâmicas dos centros urbanos regionais, e de suas funções e centralidades nas redes urbanas. Na ausência de uma cidade primaz, a rede urbana do Sul de Minas é descentralizada, tendo o protagonismo das cidades médias, dentre elas Varginha, classificada nas mais altas posições na hierarquia urbana regional, e que apresenta novas dinâmicas socioespaciais urbanas, dentre elas as novas centralidades.
\end{abstract}

Palavras-Chave: Rede Urbana; Cidades Médias; Sul de Minas; Centralidades.

\begin{abstract}
Middle-sized cities are characterized, among other aspects, by their average position in an urban network. However, economic, political, demographic, and sociocultural dynamics that inflict upon a geographical space alter, both on the cities' hierarchical positions and external influences inflicted upon them. This study aims at demonstrating the historical contexts of the Sul de Minas region urban network, emphasizing the position of the middle-sized city of Varginha. This region, situated between the important metropolitan regions of São Paulo, Rio de Janeiro and Belo Horizonte, demonstrates effective external spaces relations. From there, receive a variety of strong influences. These influences interfere in the dynamics of the regional urban centres, their functions and urban networks centrality aspects. In the absence of a major city, the urban network of the Sul de Minas is decentralized, with middle-sized cities being protagonists, Varginha being one of them, highly ranked in the regional urban hierarchy, and presenting new socio-spatial urban dynamics, among these the new centralities.
\end{abstract}

Key-words: Urban network; Middle-sized cities; Sul de Minas; Centralities. 


\section{INTRODUÇÃO}

As cidades médias apresentam posições intermediárias nas redes urbanas onde se inserem, constituindo locais que apresentam inter-relações com as metrópoles, mas, ao mesmo tempo, se caracterizam por terem influências históricas e importantes sobre as cidades e espaços rurais de sua hinterlândia. Os moradores de municípios da área de influência de uma cidade média, recorrente buscam por estruturas de educação, em especial nos níveis superior e de pós-graduação, de saúde, principalmente as de maior complexidade, mas também por produtos no comércio, e variadas formas de entretenimento, tais como cinema, shows musicais e teatrais, atividades desportivas, bares e casas noturnas, dentre outras “modernidades" não presentes nos seus municípios de residência, ou, quando há, ocorrem com menor diversidade e quantidade que nos polos regionais.

O Sul de Minas, região que tem em seu entorno as áreas de maior dinamismo econômico e demográfico do Brasil, nos últimos três séculos desenvolve relações produtivas, socioculturais e de circulação duradouras com estas áreas, perfazendo, desta forma, uma rede de cidades e espaços rurais que recebe fortes influências de metrópoles como São Paulo, Belo Horizonte, Rio de Janeiro, dentre outras. O Sul de Minas historicamente apresenta uma rede urbana sem a presença de uma cidade principal, que exerça influência em toda a região. Apesar disso, nos últimos estudos sobre a rede urbana brasileira, a exemplo do "Regiões de Influência das Cidades" (IBGE: REGIC 1966-2018), Varginha é classificada na mais alta posição na hierarquia urbana sulmineira, por vezes juntamente com outras cidades médias, tais como Poços de Caldas e Pouso Alegre.

Este artigo tem como objetivo demonstrar os contextos históricos da rede urbana do Sul de Minas, com ênfase na posição da cidade média de Varginha. E, para tanto, este escrito é dividido em três partes, além desta introdução e das considerações finais. Sendo a primeira, por meio de proposições de autores, realizada uma conceitualização da "cidade média", enfatizando seu papel intermediário em uma rede urbana.

O histórico da rede urbana do Sul de Minas, do século XIX ao século XXI, é evidenciado no próximo capítulo. Fazendo usos de mapas, dados secundários, referências bibliográficas e estudos sobre a rede urbana, são demonstradas como neste período as dinâmicas econômicas e demográficas, associadas com os sistemas de transportes, colaboraram para as diferentes posições das cidades do Sul de Minas na hierarquia urbana regional, assim como para as relações com as áreas do entorno. Em seguida é elucidada a condição de Varginha como uma cidade média, com importância na rede urbana do Sul de Minas. Devido ao crescimento populacional e econômico local, mas também por atrair moradores de municípios da sua hinterlândia, novas dinâmicas socioespaciais incidem no espaço urbano de Varginha, sendo bastante relevantes as presenças de novas centralidades, que são 
atreladas às demandas locais e regionais por produtos e serviços, e estas se apropriam de espaços privilegiados em termos de acessibilidade e/ou conteúdos sociais.

\section{CIDADES MÉDIAS: CONCEITOS E DEFINIÇÕES}

Na relação entre o desenvolvimento econômico do país e a composição dos espaços urbanos, as cidades médias brasileiras têm experimentado mudanças cuja análise, do ponto de vista da Geografia Urbana, podem ajudar a compreender o percurso contemporâneo de produção e consumo da cidade no Brasil, como a distribuição socioespacial nesses territórios e suas implicações quanto à segregação e à desigualdade social. A temática rede urbana e as cidades médias tem-se demonstrado um conjunto relevante de interesses ligados ao processo de globalização e urbanização no contexto das estratégias políticas de organização e planejamento regional.

Os conceitos e estudos relacionados à rede urbana foram importantes na França nos anos 50 do século XX e mais fortemente discutidos nas décadas de 60 e 70, onde a busca por uma definição das cidades intermediárias no pós-guerra se tonam amplas na reconstrução da Europa. Para Alvim (1998), a necessidade de descentralizar, perante a soberania de Paris, o espaço nacional, intensificouse a preocupação de integrar pessoas e atividades como forma de dinamizar o território francês.

Diante disso, segundo Amorim Filho (2015), associado a essas novas políticas implantadas pelo VI Plano de Desenvolvimento Econômico e Social (1971-1975), os franceses introduzem os estudos e pesquisas acadêmicas à categoria das cidades médias (nunca definidas e identificadas de maneira unânime e generalizada) na medida em que o processo de urbanização europeu se acelerava. Em termos de princípios e objetivos do VI Plano, integram "a distribuição mais adequada do emprego, a continuação do desenvolvimento da região oeste e o reforço das regiões de fronteira" (COSTA, 2002, p. 104).

No Brasil, com as altas taxas de migração e o crescimento do setor industrial nas décadas de 60 e 70, fez-se relevante os estudos políticos sobre o desenvolvimento regional dos espaços não metropolitanos, com os chamados Planos Nacionais de Desenvolvimento I e II (PND), respectivamente em 1971 e 1974, com a criação de um Programa para Cidades de Porte Médio, beneficiando na primeira etapa os projeto intraurbanos e posteriormente, municípios com população maior que 50.000 habitantes, levando aos gestores públicos a compreensão das realidades regionais e nacionais (SOARES, 1999, p. 55). Assim, como objetivo indispensável de aproximação dos centros urbanos e a possibilidade de conter grande parte da migração para as metrópoles, as cidades médias passaram a ter uma visibilidade evolutiva no que tange o desenvolvimento urbano-industrial. Segundo cita Amorim Filho (1984, p. 11): 
A cidade média era cada vez mais necessária porque representava uma das alternativas de manutenção do sistema socioeconômico vigente. O mau funcionamento, gerado pela concentração exagerada de homens, de atividades e de capitais, tinha de ser corrigido de algum modo, porque o mercado não conseguiu alocar os fatores produtivos de forma espacialmente equilibrada: nesse caso, as cidades médias representam válvulas de desconcentração que conseguem diminuir o mau funcionamento.

O propósito dos programas foi promover uma estruturação do sistema urbano de forma que as funções exercidas pelas cidades médias fossem parte do projeto de desenvolvimento regional, e, a exemplo de conceito, pondera, segundo Conte (2013, p. 5) "como aquelas cidades que, considerando a sua posição geográfica, população, importância socioeconômica e função dentro da hierarquia urbana da macrorregião e do país [...]”, de forma que a política de organização territorial se baseasse nas funções de desconcentração e dinamização.

A julgar a definição teórico-conceitual sobre as cidades médias, os estudos de Corrêa (2007, p.23) indicavam uma dificuldade ao classificar o termo "uma expressão vaga, aberta a múltiplos significados e impregnada de idealismo que a concebe como um ideal a ser alcançado, apresentando as vantagens da pequena cidade sem ter, contudo, as desvantagens das grandes." Para o autor, a dimensão intermediária entre a pequena e a grande cidade, a definir pelo seu tamanho, funções urbanas e densidade populacional, possibilitaram uma visão sobre o papel da cidade média em sua posição geográfica (CORRÊA, 2007).

Para Sposito (2007), as cidades de "porte médio" eram caracterizadas por seu caráter populacional, estando entre 50.000 e 500.000 habitantes, o que a diferenciava do papel exercido pelas “cidades médias”, não reconhecidas, exclusivamente, por seu elemento demográfico, mas também por sua posição na rede urbana e suas dinâmicas intraurbanas. Para a autora, as funções de mediações exercidas por pelas cidades médias na rede urbana, isto é, entre os centros urbanos e as pequenas cidades, alteram a qualidade e valores desempenhados por elas, bem como sua relação com a região.

[...] não há possibilidade de compreensão do que sejam cidades médias e pequenas sem entendimento do que é a região, porque a região é o próprio quadro de referências, é o próprio ambiente, socialmente construído, a partir das relações entre cidades médias e pequenas (SPOSITO, 2009, p.18).

Segundo Santos (2005), o pós década de 1970, do ponto de vista da urbanização e industrialização brasileira, foi período em que houve o aumento de cidades com o número superior a 100.000 habitantes, causando alterações significativas nos agrupamentos urbanos com essa população. Este processo auxiliou o autor na defesa desse limite populacional para a classificação das cidades médias, justificado na complexidade e diversificação do trabalho, bens e serviços. O número de núcleos urbanos com população entre 100.000 e 500.000 habitantes teve um crescimento de 143\%, de 88 cidades dentro desse contingente na década de 1980 para 214 em 2010 (IBGE, 1980; 2010). 
Em termos qualitativos, se antes o papel das cidades médias era de restrita mediação entre pequenas cidades e as metrópoles, hoje em dia sua atuação desempenha funções econômicas bem mais complexas. Pela grande - e competitiva - especialização funcional que desenvolveram, alguns desses núcleos têm se destacado em questões como a gestão técnica da produção agrícola e o oferecimento de bens e serviços cada vez mais diferenciados, o que, somado ao incremento de importantes funções como saúde e educação, confere-lhes o papel de liderança regional (SILVEIRA, 2002).

\section{A REDE URBANA DO SUL DE MINAS, DO SÉCULO XIX AO SÉCULO XXI}

Apesar de haver algum povoamento além-indígena no Sul de Minas, foi apenas no final do século XVII e início do século XVIII que foram formados os primeiros arraiais e povoados, tais como Campanha, Aiuruoca e Baependi (STEFANI, 2016). As povoações formadas ao longo dos caminhos de tropas, que interligavam as regiões mineradoras da área central da capitania de Minas Gerais e os centros urbanos de São Paulo e Rio de Janeiro, foram numerosas, e em muitos casos progrediram para se consolidarem como cidades, situações estas que aconteceram, por exemplo, em Pouso Alegre, Pouso Alto e Passa Quatro (DEFFONTAINES, 1944).

A criação do Termo da Vila de Campanha, em 1798, a partir da emancipação desde São João del Rey, pode ser considerada como uma primeira delimitação do que constitui a Macrorregião de Planejamento do Sul de Minas na atualidade. No mapa da figura 1 são demonstradas as localidades com maior centralidade urbana da região, na década de 1830, quando algumas vilas já haviam se emancipado, como Aiuruoca, Baependi, Lavras e Pouso Alegre (STEFANI, 2016).

A produção de gêneros alimentícios voltados ao abastecimento das cidades mineradoras (Vila Rica - atual Ouro Preto, São João Del Rey e Congonhas) e da capital colonial (Rio de Janeiro) que possibilitou a estruturação da economia, das relações sociais e da produção espacial do Sul de Minas ao longo dos séculos XVIII e XIX (FURTADO, 1976). As áreas ao leste e do centro do Sul de Minas eram as mais populosas, as que possuíam maior desenvolvimento econômico e onde havia uma rede mais densa de caminhos (PAIVA, 1996; MELLO FILHO; SANTOS JÚNIOR, 2006). Nestas áreas estavam as localidades com maior centralidade no início do século XIX, com destaques para Pouso Alegre, São Gonçalo do Sapucaí e Andrelândia, na classificação de Stefani (2016), e, especialmente Campanha, a de maior centralidade dentre todas da região tanto nas classificações de Stefani, como nas realizadas por Rodarte ${ }^{1}$ (1999).

\footnotetext{
${ }^{1}$ Rodarte (1999) levou em conta as dinâmicas regionais e fluxos entre as agências de correio da província de Minas Gerais, e também as características produtivas locais das povoações mineiras do período (freguesias, vilas e cidades). O adensamento dos dados a partir de métodos estatísticos levou ao agrupamento das cidades de acordo com suas centralidades na "rede de correios da província", e da diversidade de atividades consideradas "urbanas", que foram representadas pelos trabalhadores liberais (médicos, professores, advogados, farmacêuticos, escrivães, dentre outros), os
} 


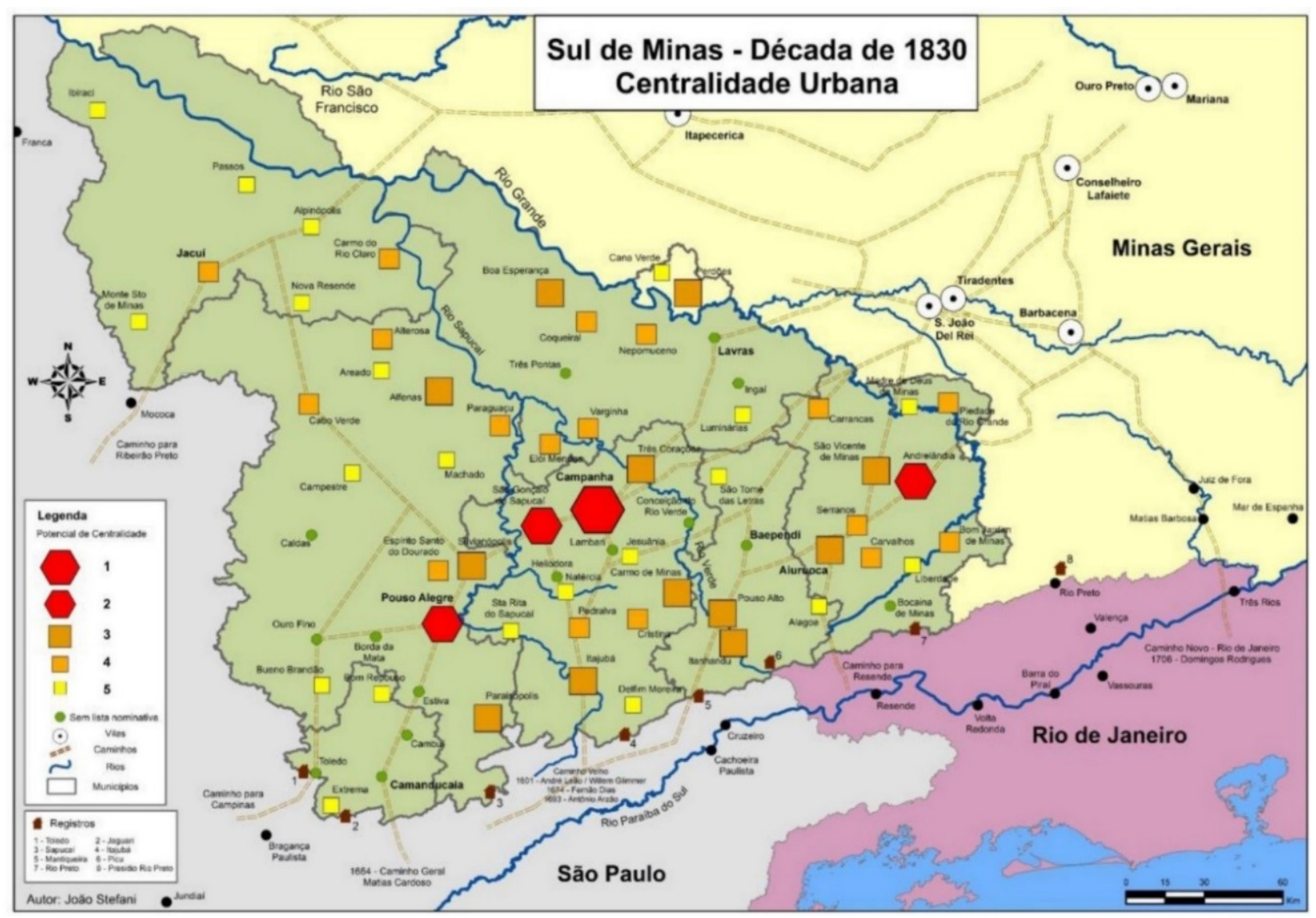

Figura 1 - Centralidade Urbana no Sul de Minas, na década de 1830.

Fonte: STEFANI (2016).

Os mapas da figura 2 demonstram as cidades de Minas Gerais com maiores centralidades, em dois momentos do século XIX.

As relações entre crescimento populacional e as dinâmicas produtivas foram fundamentais para as mudanças nas centralidades urbanas de Minas Gerais no século XVIII. No primeiro momento (1831-1840), as cidades mineradoras, e alguns centros urbanos das proximidades, foram as que apresentaram maior centralidade, sendo Mariana e Serro as com hierarquia mais elevada. No segundo, houve nítida dispersão dos núcleos de maior centralidade pelo território mineiro, e as cidades de Juiz de Fora e Mar de Espanha, localizadas na Zona da Mata, foram as de maior posição hierárquica, e isto é resultado da expansão da cafeicultura na referida região. No Sul de Minas, enquanto no primeiro período a cidade de Campanha, e em menor grau São Gonçalo do Sapucaí e Silvianópolis, eram as que possuíam certa centralidade, no ano de 1872 houve um expressivo acréscimo no número de cidades, sendo Campanha, Baependi, Pouso Alegre e Lavras as de maior relevância na rede urbana mineira.

comerciantes e os artesãos e operários de indústrias. Stefani (2016), por sua vez, fazendo uso de métodos estatísticos, teve como parâmetro as atividades profissionais utilizadas por Rodarte, dando pesos diferenciados para a presença/quantidade de profissionais liberais (peso 40), comércio e circulação (30), Estado (20), e Artesanato (10 pontos), e estipulou 5 níveis de centralidades para as vilas e distritos do Sul de Minas. 


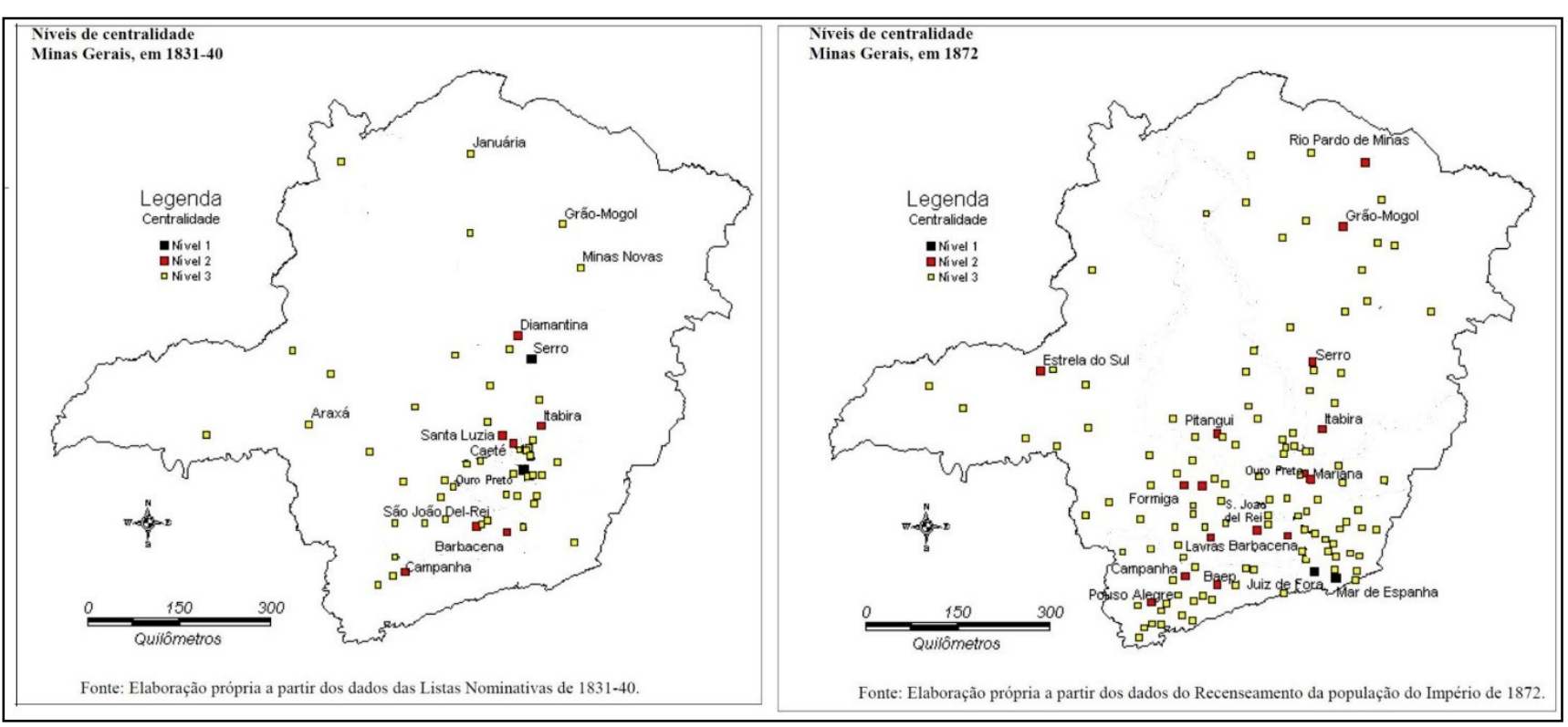

Figura 2 - Centralidades das cidades de Minas Gerais, em dois momentos do século XIX.

Fonte: RODARTE (1999), modificado pelos autores.

Como extensão da economia fluminense, a Zona da Mata foi a primeira e a principal região produtora de café de Minas Gerais. Na década de oitenta do século XIX, enquanto a Zona da Mata possuía 602 quilômetros de ferrovias, o Sul de Minas possuía $269 \mathrm{~km}$, e a região Central apenas 135 quilômetros (GIOVANINI; MATOS, 2004). Neste momento, ainda anterior a fundação de Belo Horizonte, que se deu em 1897, a Zona da Mata era a principal região econômica de Minas Gerais, e Juiz de Fora se consolidara como a maior e mais rica cidade do estado (Figura 3).

No final do século XIX, a cafeicultura avançou em termos espaciais no Sul de Minas, e elucida esta situação o fato que a região aumentou sua participação de 5,0\% em 1882 para 33,3\% no total das exportações de café de Minas Gerais em 1906, sendo que o volume da produção mineira mais que triplicou no período (GIOVANINI; MATOS, 2004). Nesta conjuntura, houve uma expansão da rede ferroviária pelo Sul de Minas, a atração de afluências de migrantes brasileiros e estrangeiros, e seus municípios passaram a apresentar maior importância econômica, o que pode ser observado na tabela da figura 3. Em 1889 não havia nenhum município do Sul de Minas dentre os de maior renda, que passaram a ser dois em 1910 (Poços de Caldas e Itajubá) e quatro em 1937 (Poços de Caldas, Pouso Alegre, Itajubá e Caxambu). Ao mesmo tempo, Belo Horizonte gradativamente se consolidou como a maior economia estadual, enquanto os municípios da Zona da Mata foram perdendo importância, já que haviam sete dentre os mais ricos em 1889, e apenas um, Juiz de Fora, em 1937 (WIRTH, 1982). 


\begin{tabular}{|c|c|c|c|}
\hline \multicolumn{4}{|c|}{$\begin{array}{l}\text { Municipalidades classificadas por renda, 1889-1937 } \\
\text { (Em contos arredondados) }\end{array}$} \\
\hline Municipalidade & Renda & Municipalidade & Renda \\
\hline 1889 & & 1910 & \\
\hline $\begin{array}{l}\text { Juiz de Fora (M) } \\
\text { Além-Paraiba (M) } \\
\text { Ouro Preto (C) } \\
\text { Leopoldina (M) } \\
\text { Sảo João del Rei (C) } \\
\text { Mar de Espanha (M) } \\
\text { Uberaba (T) } \\
\text { Barbacena (C) } \\
\text { Muriaé (M) } \\
\text { Diamantina (N) } \\
\text { Pomba (M) } \\
\text { Ponte Nova (M) }\end{array}$ & $\begin{array}{l}88 \\
46 \\
38 \\
37 \\
29 \\
28 \\
20 \\
20 \\
20 \\
17 \\
15 \\
14\end{array}$ & $\begin{array}{l}\text { Belo Horizonte (C) } \\
\text { Juiz de Fora (M) } \\
\text { Uberaba (T) } \\
\text { Barbacena (C) } \\
\text { Ponte Nova (M) } \\
\text { Carangola (M) } \\
\text { Poços de Caldas (S) } \\
\text { Além Paraiba (M) } \\
\text { Itajubá (S) } \\
\text { Sảo João del Rei (C) } \\
\text { Cataguases (M) } \\
\text { Leopoldina (M) }\end{array}$ & $\begin{array}{l}945 \\
630 \\
376 \\
212 \\
168 \\
112 \\
128 \\
128 \\
126 \\
120 \\
111 \\
107\end{array}$ \\
\hline 1923 & & 1937 & \\
\hline $\begin{array}{l}\text { Belo Horizonte (C) } \\
\text { Juiz de Fora (M) } \\
\text { Uberaba (T) } \\
\text { São João del Rei (C) } \\
\text { Barbacena (C) } \\
\text { Carangola (M) } \\
\text { Poços de Caldas (S) } \\
\text { Ouro Fino (S) } \\
\text { Ponte Nova (M) } \\
\text { Manhuaçu (M) } \\
\text { Ubá (M) } \\
\text { Uberlândia (T) }\end{array}$ & $\begin{array}{r}2,575 \\
1,269 \\
660 \\
515 \\
507 \\
490 \\
360 \\
342 \\
301 \\
300 \\
282 \\
281\end{array}$ & $\begin{array}{l}\text { Belo Horizonte (C) } \\
\text { Juiz de Fora (M) } \\
\text { Uberaba (T) } \\
\text { Uberlândia (T) } \\
\text { Poços de Culdas (S) } \\
\text { Barbacena (C) } \\
\text { São João del Rei (C) } \\
\text { Araguari (T) } \\
\text { Pouso Alegre (S) } \\
\text { Itajubá (S) } \\
\text { Caxambu (S) } \\
\text { Teófilo Ottoni (E) }\end{array}$ & $\begin{array}{r}33,407 \\
3,687 \\
1,762 \\
1,137 \\
1,007 \\
1,093 \\
1,085 \\
835 \\
739 \\
718 \\
707 \\
683\end{array}$ \\
\hline \multicolumn{4}{|c|}{$\begin{array}{l}\text { FONTE: Renda municipal: 1889: Senna, A terra mineira, 2:276. 1910: Brasil, A nuório es- } \\
\text { tatístico, ano I, vol. 2, pp. 350-61. 1923: Brasil, Estatfstica das Finanças, Tabela XXIX, } \\
\text { pp. I10-20. 1937: Menelick de Carvalho, A revolução de } 30 \text { e o municiplo (Quadros de- } \\
\text { monstrativos da arrecadaçăo efetuada pelos municlpios mineiros no perlodo de } 1931 \text { a } \\
\text { 1938), n.p. } \\
\text { NOTA: As sub-regiỏes salo indicadas entre parênteses: Centro, Leste, Mata, Norte, } \\
\text { Sul. Triângulo, Oeste. }\end{array}$} \\
\hline $\begin{array}{l}\text { Fonte - WIRTH, Jof } \\
\text { Rio de Janeiro: Paz }\end{array}$ & $\begin{array}{l}\text { fiel da balança: } \mathrm{N} \\
\text { a, } 1982 .\end{array}$ & s Ge rais na feder açāo brasileira, 188 & \\
\hline
\end{tabular}

Figura 3 - Municípios mineiros de acordo com a produção econômica, entre 1889 e 1937. (Os municípios do Sul de Minas estão demarcados em laranja).

Fonte: WIRTH (1982, p.65), modificado pelos autores.

Por iniciativas estatais, mas também privadas, a rede ferroviária se expandiu no Sul de Minas, e em especial no período entre 1879 e 1898 (BATISTA, BARBOSA; GODOY, 2012). As linhas férreas adentraram ao Sul de Minas, por meio da Rede Minas-Rio, interligando Três Corações com Cruzeiro (SP), e dali para São Paulo e Rio de Janeiro pela E.F. Dom Pedro II, posteriormente Central do Brasil (CASTILHO, 2012). A ligação ferroviária neste trecho, além de favorecer o transporte de mercadorias, também dinamizou a atividade turística, com destaque para as estâncias hidrominerais de São Lourenço, Caxambu, Lambari e Cambuquira, que formam o "Circuito das Águas", que passaram a estar interligadas com a cidade do Rio de Janeiro (ANDRADE et al., 2014).

As últimas décadas do século XX foram de grandes transformações nos campos políticos (Proclamação da República, em 1889), trabalhistas (Abolição da Escravatura, em 1888), demográficos (imigração internacional), e econômicas, neste contexto especialmente pela expansão da cafeicultura em direção ao oeste, atingindo áreas ainda pouco povoadas do Sul de Minas, do interior de São Paulo, e posteriormente do Norte do Paraná. E, neste contexto, a rede ferroviária do Sul de Minas passou a ser gradativamente mais integrada com a rede paulista, por intermédio da Companhia Mogiana, que atingiu a estância turística de Poços de Caldas em 1886 (ANDRADE, 2005), e, já no século XX, os trilhos da Mogiana chegaram às áreas de Guaxupé, São Sebastião do 
Paraíso e Passos, conectando com a E.F. Muzambinho na estação de Jureia, no atual município de Monte Belo. A E.F. Muzambinho interligava Três Corações a Muzambinho, passando por Varginha em 1892 (CASTILHO, 2012), e era complementada por ramais particulares, como a E.F. Machadense (Machado - Estação Gaspar Lopes, em Alfenas) e a E.F São Gonçalo (São Gonçalo do Sapucaí Campanha).

A Estrada de Ferro Sapucaí ligava a Estrada de Ferro Minas-Rio ao limite das províncias de Minas Gerais e São Paulo, onde a mesma se conectava com a Estrada de Ferro Mogiana na estação Sapucaí (atual município de Jacutinga). As linhas foram construídas em trechos de leste em direção a oeste, que foram sendo inaugurados ao longo da década de 1890, sendo a estação de Itajubá inaugurada em 1891 e a de Pouso Alegre em 1895 (CASTILHO, 2012; SILVA, 2012).

Após fusões e mudanças de controle, toda a rede ferroviária sulmineira passou a fazer parte da Rede Mineira de Viação, excetuando os trechos pertencentes a Mogiana (Figura 4). E a melhor circulação pelo território favoreceu o transporte da produção regional, em especial de gêneros alimentícios, para outros centros urbanos brasileiros, como São Paulo e Rio de Janeiro, e o escoamento de café em direção aos portos do Rio de Janeiro e, em especial de Santos. A população do Sul de Minas passou de 455.200 habitantes em 1872 (MELLO SILVA; SANTOS JÚNIOR, 2006), para 1.252.528 no ano de 1940 (IBGE: Censo Demográfico, 1940).

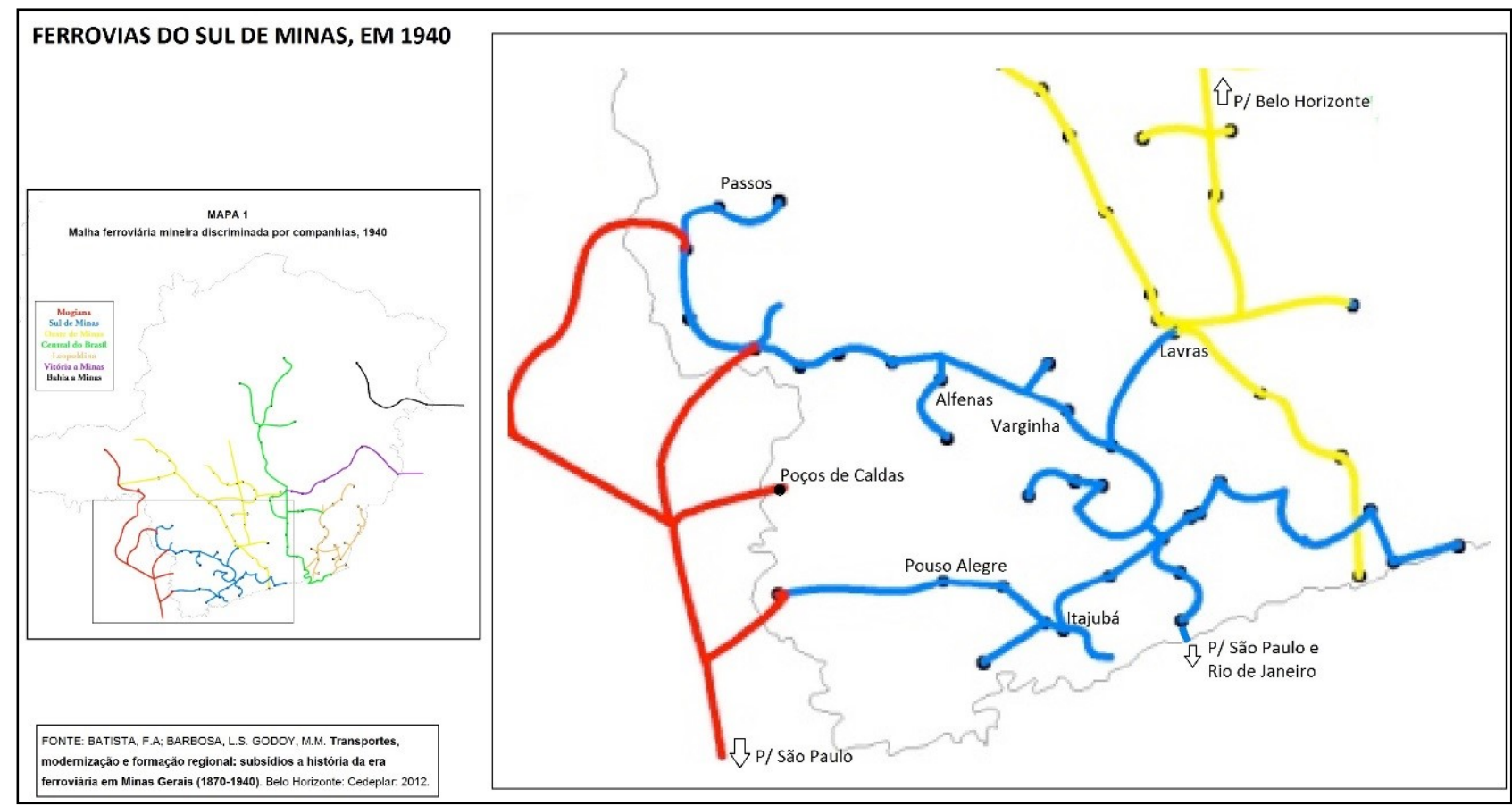

Figura 4 - Rede Ferroviária do Sul de Minas, em 1940.

Fonte: BATISTA, BARBOSA; GODOY, 2012, modificado pelos autores. 
Na primeira metade do século XX as cidades do Sul de Minas, e em especial as de maior população e importância regional, passaram por significativas mudanças em suas fisionomias, estruturas, economias e modos de vida cotidiano. Com a interligação com outros centros urbanos, por intermédio das ferrovias, a implantação e a difusão da energia elétrica, e o crescimento populacional, os estabelecimentos comerciais passaram a receber novos produtos, que passaram a ser consumidos pelas populações locais e mesmo do entorno; ao mesmo tempo, foram fundadas escolas e faculdades, hospitais, bancos, e espaços culturais como bibliotecas, cinemas e teatros. Ademais, as cidades, e com mais ênfase suas áreas centrais, receberam benfeitorias paisagísticas e de infraestruturas, como calçamento e iluminação de vias, sistema de saneamento, edificações com diferentes funções, mercados municipais, e praças e jardins.

Como legado de sua posição de capital federal, e de aspectos econômicos e socioculturais, o Rio de Janeiro exercia influência em considerável extensão do Sul de Minas, em especial nas áreas a centro e a leste da região (Figura 5). Entretanto, é válido destacar que em Lavras a influência da referida metrópole era partilhada com a de Belo Horizonte, enquanto que em Varginha e em Itajubá a influência do Rio de Janeiro era partilhada com São Paulo. O oeste do Sul de Minas, onde se situam Poços de Caldas e Pouso Alegre, era polarizado pela metrópole paulistana.

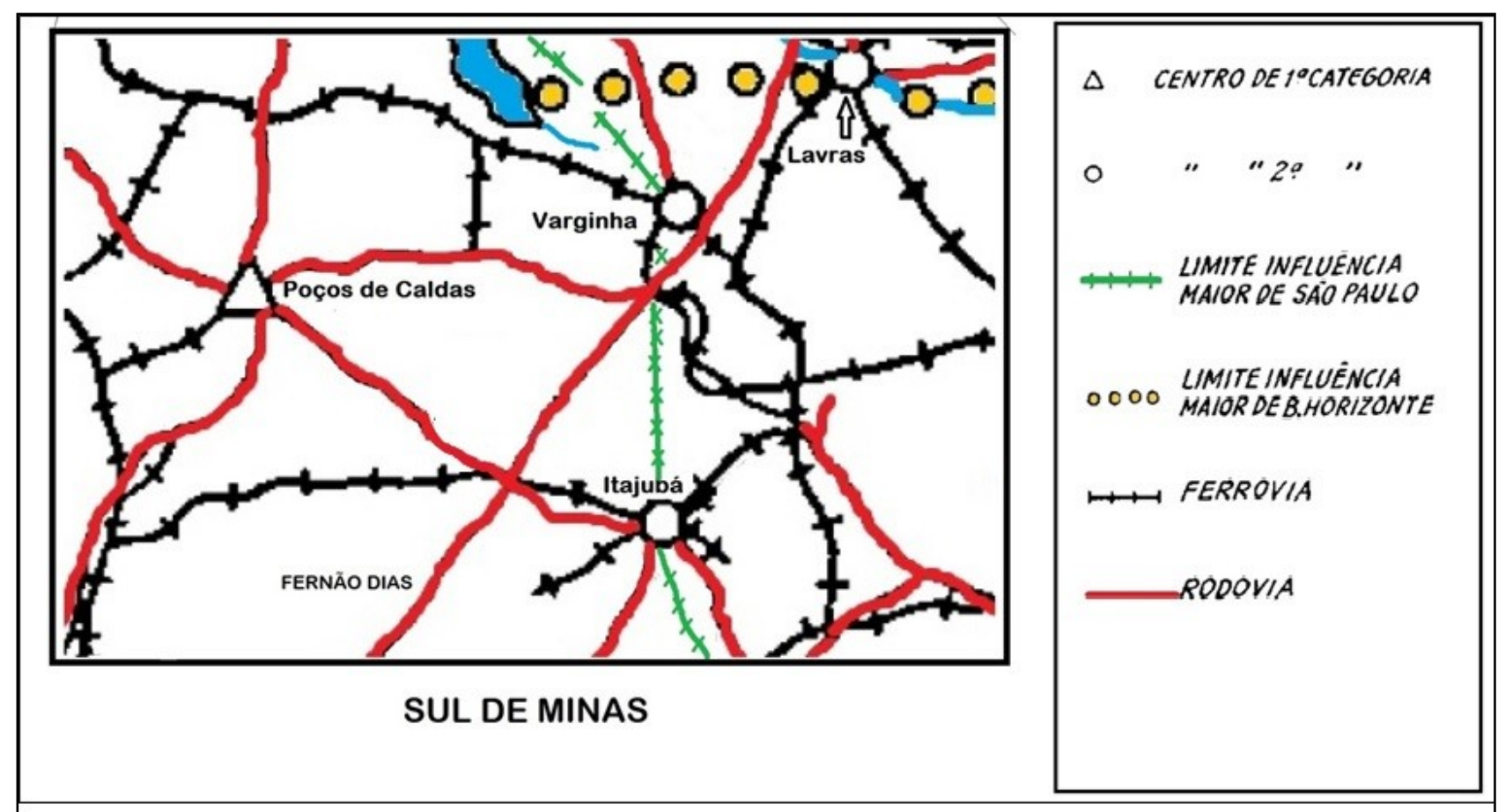

Figura 5 - Cidades do Sul de Minas na Rede Urbana Regional.

Fonte: GEIGER; DAVIDOVICH (1961, p. 317 - Área de Influência do Rio de Janeiro), adaptado pelos autores.

Assim, a influência da capital federal era mais intensa nas áreas de São Lourenço e Andrelândia (a leste), significativa nas regiões de Lavras, Varginha e Itajubá, e reduzia na medida que se dirigia a oeste e ao norte, respectivamente pelas influências de São Paulo e Belo Horizonte; 
estas influências externas, por fatores demográficos, econômicos, e dos sistemas de transportes, em especial o rodoviário, vão se alterar a partir de então, como serão demonstrados mais à frente.

A cidade de Poços de Caldas foi considerada, na classificação de Geiger e Davidovich (1961), como “centro de primeira categoria”, enquanto Itajubá, Varginha e Lavras se posicionavam como "centro de segunda categoria"2. Pouso Alegre, Passos e Alfenas, de acordo com a classificação dos autores, não apresentavam importância mais efetivas na rede urbana sulmineira da época. Entretanto, o papel de "principal cidade do Sul de Minas”, já nesta época, era difícil de se precisar, pois, de acordo com Bernardes (1963), Itajubá era a "principal cidade do Sul de Minas”, por sua vez, no primeiro estudo das "Regiões de Influência das Cidades" (IBGE: REGIC, 1966), Varginha era a cidade com a maior importância na rede urbana regional.

Divinópolis no Oeste de Minas, Montes Claros no Norte e Juiz de Fora na Zona da Mata são apontadas, em diversas classificações da rede urbana estadual e nacional, como as "cidades principais" em suas regiões. Nas pesquisas lideradas por Amorim Filho, sobre as cidades médias de Minas Gerais, estas sempre estiveram posicionadas como as de maior hierarquia no contexto das macrorregiões em que se situam (AMORIM FILHO et al., 2007). O mesmo ocorre nos estudos das "Regiões de Influência das Cidades" (1966, 1978, 1993, 2007 e 2018) e da "Caracterização e tendências da rede urbana do Brasil” (IPEA, 2001). Já no Sul de Minas, estes estudos, mas também autores como Bernardes (1963), Azevedo (1971) e Andrade (2014), evidenciaram o fato da região possuir uma rede urbana descentralizada, onde a função de centralidade é partilhada entre cidades médias, como Poços de Caldas, Varginha, Pouso Alegre, Passos, Itajubá, Lavras e Alfenas, e incluindo, por vezes, outras, como São Lourenço e Três Corações.

A posição geográfica do Sul de Minas colaborou para que, no decorrer dos últimos séculos, a região participasse com considerável importância no abastecimento, em especial através dos produtos agropecuários e mais recentemente de artigos manufaturados, do amplo mercado consumidor que foi se consolidando em seu entorno. Em decorrência disto, no final do século XIX, a própria implantação da rede ferroviária regional se deu almejando a integração entre as áreas produtoras do Sul de Minas com os mercados de São Paulo e do Rio de Janeiro, e não a interligação entre suas principais cidades, o que desfavoreceu a maior coesão entre os centros urbanos regionais, e mesmo a consolidação de uma "cidade primaz" (SAES, COSENTINO; GAMBI, 2012).

A implantação das rodovias favoreceu a maior integração entre as principais cidades da região, assim como com outras regiões do país. Poços de Caldas, por exemplo, passou a ter ligação

\footnotetext{
${ }^{2}$ De acordo com as definições de Geiger e Davidovich (1961), os centros de primeira categoria são constituídos por cidades com população entre 10 e 30 mil habitantes, que possuem entroncamentos ferroviários, ou alguma projeção industrial, geralmente de bens de consumo; os centros de segunda ordem são constituídos por cidades com população entre 10 e 20 mil habitantes, e seu raio de influência regional são menores que dos centros urbanos com hierarquia superior.
} 
mais efetiva com o restante da região do Sul de Minas, que até então era restrita a precárias estradas de terra ou por um grande deslocamento por ferrovia, onde tinha a necessidade de baldeação em cidades do estado de São Paulo (ANDRADE, 2014).

A inauguração da Fernão Dias, no início dos anos 60, ligando São Paulo e Belo Horizonte, favoreceu a circulação entre cidades como Pouso Alegre, Lavras e Varginha dentre outras. Com a opção pelo transporte rodoviário de pessoas e mercadorias no contexto regional, o transporte ferroviário de passageiros no Sul de Minas hoje é inexistente, havendo apenas alguns pequenos trajetos com funções turísticas. A distribuição espacial destas vias é elucidada na figura 6 .

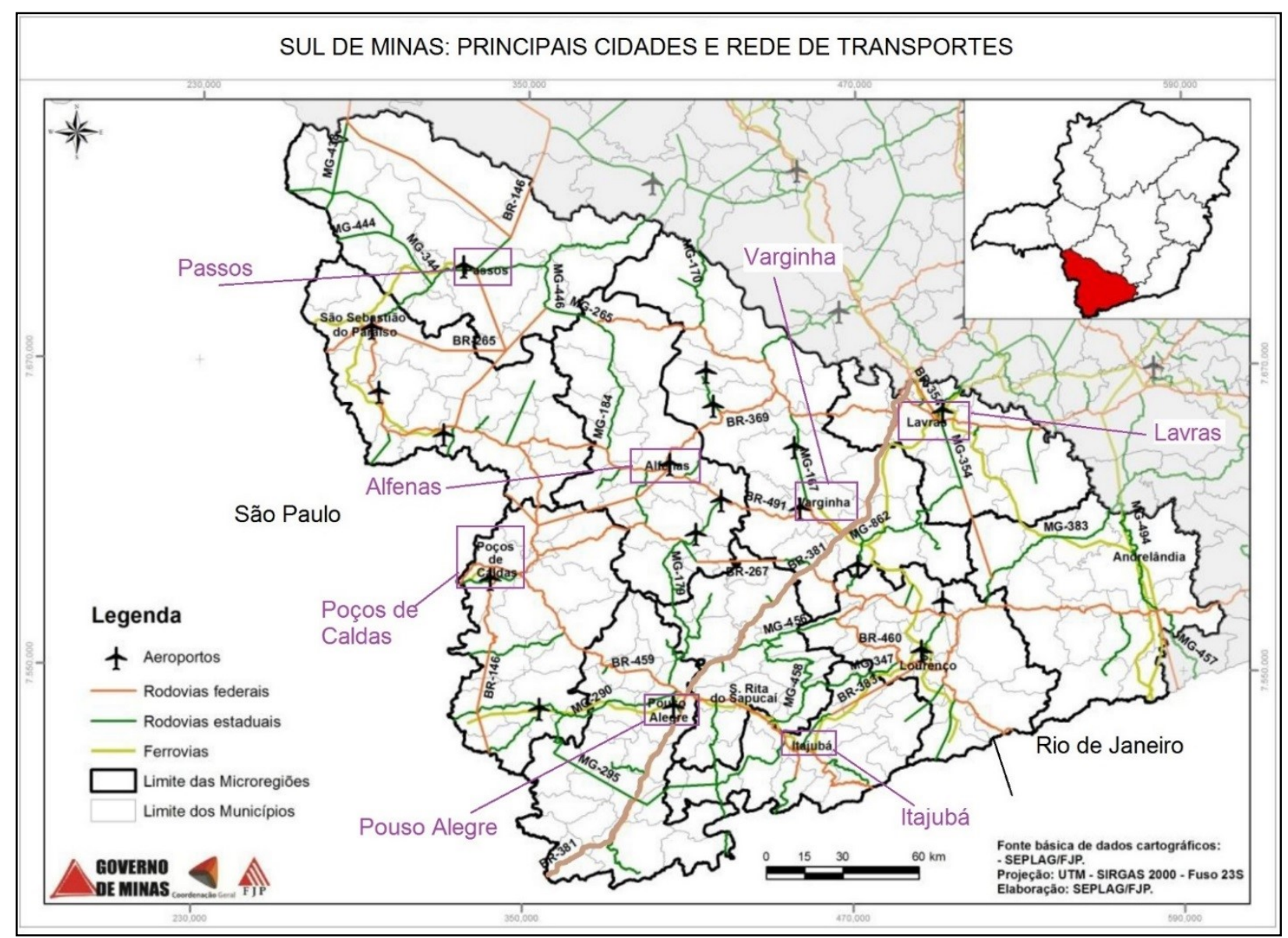

Figura 6 - Cidades médias e sistemas de transportes no Sul de Minas.

Fonte: Gov. de Minas Gerais, Caderno Regional do Sul de Minas (2014), adaptado pelos autores.

No período anterior ao início dos anos 80 do século $\mathrm{XX}$, as regiões metropolitanas, em especial São Paulo e Rio de Janeiro, concentravam significativa parcela das atividades produtivas e absorveram a maior parte dos migrantes que se deslocavam a partir de espaços rurais e pequenas cidades; todavia, a partir de então se iniciou um processo de desconcentração da migração e intensificou a urbanização estruturada em rede (MATOS, 2012). Neste contexto, seja em decorrência do processo de desconcentração industrial, principalmente a partir de São Paulo, mas também o desenvolvimento de atividades agropecuárias, comerciais, de serviços, turísticas, dentre outras, as 
cidades médias passaram a apresentar significativo desenvolvimento econômico, crescimento populacional, e, por consequência, aumentaram suas importâncias nas redes urbanas regionais.

No Sul de Minas, entre 1980 e 2010 (IBGE: Censos Demográficos), as principais cidades médias apresentaram os seguintes crescimentos de suas populações urbanas: Pouso Alegre 135,6\% (50.758 para 119.602), Alfenas 116,0\% (32.027 para 69.176), Varginha 106,6\% (57.657 para 119.099), Lavras 94,7\% (45.119 para 87.835), Poços de Caldas 82,8\% (81.399 para 148.785), Passos $77,0 \%$ (56.973 para 100.866) e Itajubá 54,9\% (53.441 para 82.785) (Figura 7).

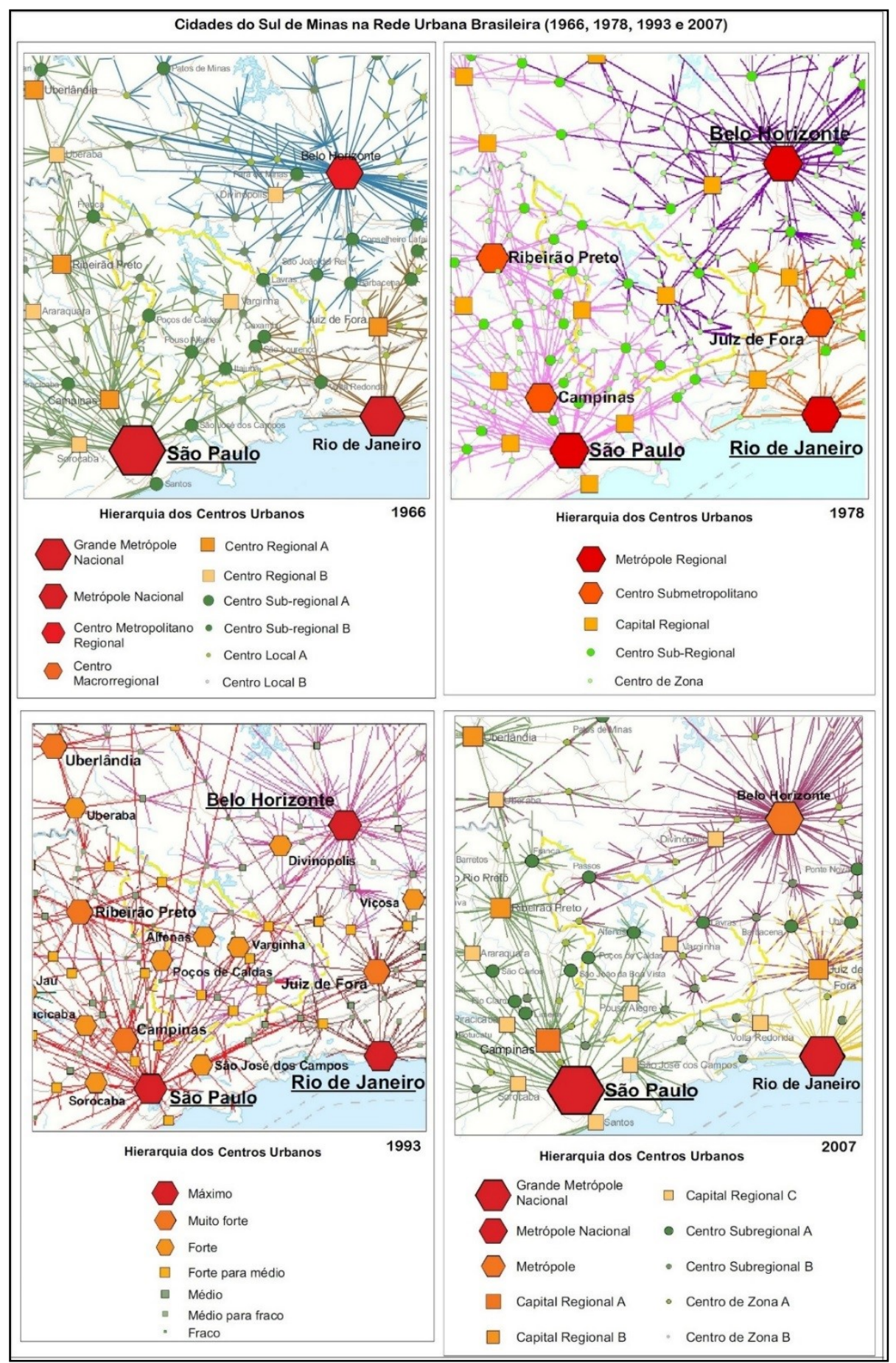

Figura 7 - As cidades sulmineiras na rede urbana nacional.

Fonte: IBGE (REGIC, 2007). Modificado pelos autores. 
Em 1966, no primeiro estudo das "Regiões de Influência das Cidades" (IBGE: REGIC), o Rio de Janeiro apresentava importante polarização sobre considerável parcela do Sul de Minas, em especial nas estâncias hidrominerais de São Lourenço e Caxambu e na região mais a leste (Andrelândia e Cruzilia). São Paulo exercia influência primaz em todo o centro e o oeste do Sul de Minas, o que englobava as cidades de Itajubá, Varginha, Pouso Alegre, Passos, Alfenas e Poços de Caldas. A influência de Belo Horizonte era mais relevante apenas em Lavras e nas pequenas cidades do entorno, situação advinda da herança histórica dos sistemas econômicos e de transportes de até então, já que, menos de uma década antes desta classificação, a ligação entre as cidades sulmineiras e a capital estadual ainda não contava com a rodovia Fernão Dias e outras estradas.

Nas classificações seguintes (1978, 1993, 2007), Belo Horizonte expandiu sua área de influência sobre o Sul de Minas, em especial nas cidades de Varginha, Alfenas, Passos, São Lourenço e nas localidades vizinhas. Enquanto isso, a polarização do Rio de Janeiro se reduziu em ampla parcela do Sul de Minas, tendo influência mais efetiva apenas no extremo leste, na região de Andrelândia, em especial por intermédio de cidades médias pertencentes a sua rede, como Volta Redonda (RJ) e Juiz de Fora, sendo que nesta última, na classificação de 2007, pertencia, ao mesmo tempo, às Regiões de Influência de Belo Horizonte e do Rio de Janeiro. A polarização de São Paulo se manteve dominante sobre as cidades médias de Poços de Caldas, Pouso Alegre e Itajubá, além das cidades menores do entorno destas nas classificações de 1978, 1993 e 2007; da rede paulista também são bastante significativas as influências de Campinas, Ribeirão Preto, São José dos Campos, dentre outras, sobre áreas da região sulmineira.

Com relação as cidades médias do Sul de Minas, como anteriormente mencionado, não há na região uma "cidade primaz", no entanto, ao se observar os mapas da figura 7, e as informações na tabela 1, se percebe que há certas oscilações nas posições destas cidades na rede urbana, porém Varginha sempre se manteve na maior posição hierárquica no contexto regional.

Tabela 1: Posição das cidades médias do Sul de Minas na rede urbana regional (1966-2007).

\begin{tabular}{|c|c|c|c|c|}
\hline & 1966 & 1978 & 1993 & 2007 \\
\hline Capital Regional & Varginha & $\begin{array}{l}\text { Varginha } \\
\text { Poços de Caldas }\end{array}$ & $\begin{array}{l}\text { Varginha } \\
\text { Poços de Caldas } \\
\text { Alfenas }\end{array}$ & $\begin{array}{l}\text { Varginha } \\
\text { Pouso Alegre }\end{array}$ \\
\hline Centro Sub Regional A & $\begin{array}{l}\text { Poços de Caldas } \\
\text { Pouso Alegre } \\
\text { Itajubá } \\
\text { Lavras }\end{array}$ & $\begin{array}{l}\text { Pouso Alegre } \\
\text { Itajubá } \\
\text { Lavras } \\
\text { Passos } \\
\text { Alfenas }\end{array}$ & $\begin{array}{l}\text { Pouso Alegre } \\
\text { Itajubá } \\
\text { Lavras } \\
\text { Passos }\end{array}$ & $\begin{array}{l}\text { Poços de Caldas } \\
\text { Alfenas } \\
\text { Lavras } \\
\text { Passos }\end{array}$ \\
\hline Centro Sub Regional B & $\begin{array}{l}\text { Passos } \\
\text { Alfenas }\end{array}$ & & & Itajubá \\
\hline
\end{tabular}

Fonte: IBGE (REGIC, 1966, 1978, 1993, 2007). Organizado pelos autores. 
Ao analisar as posições das mais diversas cidades em uma rede urbana, é de se levar em conta questões diversas, como economia, aspectos demográficos, históricos e culturais, a disponibilidade e ligações dos sistemas de transportes e as posições geográficas em âmbitos regionais, nacional e mesmo global; todas estas, em diferentes intensidades, colaboram para que uma cidade apresente maior ou menor centralidade. Neste contexto, diversas mudanças ocorreram no Sul de Minas, mas também em seu entorno, onde, inclusive, estão importantes metrópoles e cidades médias, que, pelas situações acima descritas, exercem influências sobre o espaço sulmineiro.

Varginha, mesmo se mantendo na maior posição hierárquica no Sul de Minas em todas as classificações, não conseguiu impor sua centralidade à toda a região, sendo bastante restritas as suas influências nas áreas mais distantes, em especial nas polarizadas por Poços de Caldas, Itajubá, Passos, assim como as localizadas ao sul e a oeste de Pouso Alegre. A relativa semelhança nos tamanhos funcionais destas cidades fora inclusive demonstrada nas pesquisas lideradas por Amorim Filho et al., (2007), onde Varginha, Pouso Alegre e Poços de Caldas foram consideradas como "Cidades Médias de Nível Superior” em 1982, 1999 e 2007, Passos em 1999 e 2007, e Itajubá em 1982 e 1999, sendo está, na última classificação, considerada como "Cidade Média Propriamente Dita".

São algumas características das “Cidades Médias de Nível Superior”:

As cidades aqui incluídas são sempre visualizadas, em qualquer hierarquização, como
cidades médias (...). No interior de suas próprias regiões, são encaradas pela população
regional como cidades grandes. São cidades que possuem um dinamismo demográfico
sustentado (...). São cidades que desenvolveram, paralelamente à indústria, dinâmicos setores
de comércio e de serviços. Assim, essas cidades, além de fortalecerem sua posição e suas
ligações no domínio regional, começam a estender essas ligações a pontos situados para além
desses domínios. São, em síntese, cidades de estruturas já bem consolidadas e cujo
crescimento futuro parece, sem dúvida. (AMORIM FILHO et al., 1982, p. 41 apud AMORIM
FILHO; RIGOTTI; CAMPOS, 2007, p.09).

A posição mais "central” de Varginha, no âmbito da região do Sul de Minas, colabora para que, gradativamente, ela fosse aumentando sua importância na rede urbana regional. Campanha, certamente a mais importante cidade no século XIX, manteve apenas maior relevância no campo religioso (sede de diocese), e alguma educacional, por conta do Colégio Nossa Senhora do Sion, hoje um Campus da Universidade do Estado de Minas Gerais. Situada a quarenta quilômetros desta, Varginha acabou ficando a "meio caminho" das áreas à oeste, onde a cafeicultura apresentou e apresenta grande importância econômica (Alfenas, Machado, Campos Gerais), e à leste, onde tradicionalmente a pecuária leiteira e o turismo são importantes para a economia (Três Corações, Conceição do Rio Verde e o Circuito das Águas). E, com estas cidades, Varginha era interligada por meio de ferrovias e depois por rodovias, assumindo, assim, importante papel de centro comercial, bancário, de prestações de serviços públicos e privados, e do sistema produtivo relacionado ao café. 
Durante as classificações do REGIC, por vezes Varginha chegou a polarizar, mesmo que em algumas vezes de forma partilhada, outras cidades médias, como Alfenas em 1966, 1978 e na mais recente de 2018, e Lavras e Pouso Alegre, na classificação de 1993. Ademais, Varginha também exerce influência, em todos os períodos, sobre cidades populosas e com certo dinamismo econômico, como Três Corações e Três Pontas (Figura 8). E, em alguns destes estudos do REGIC, polarizou cidades “intermediárias” em termos populacionais, econômicos e de posições na rede urbana, tais como São Lourenço, Caxambu, Boa Esperança, Machado e Campo Belo. Quanto as Regiões de Influência das Cidades Médias do Sul de Minas, de 2007, a que tem em Varginha como polo era a que possuía maiores população, Produto Interno Bruto, e densidade de centros intermediários (nove), contra quatro de Pouso Alegre, dois de Alfenas e Passos, um de Poços de Caldas e Itajubá, e nenhum de Lavras (ANDRADE, 2014).

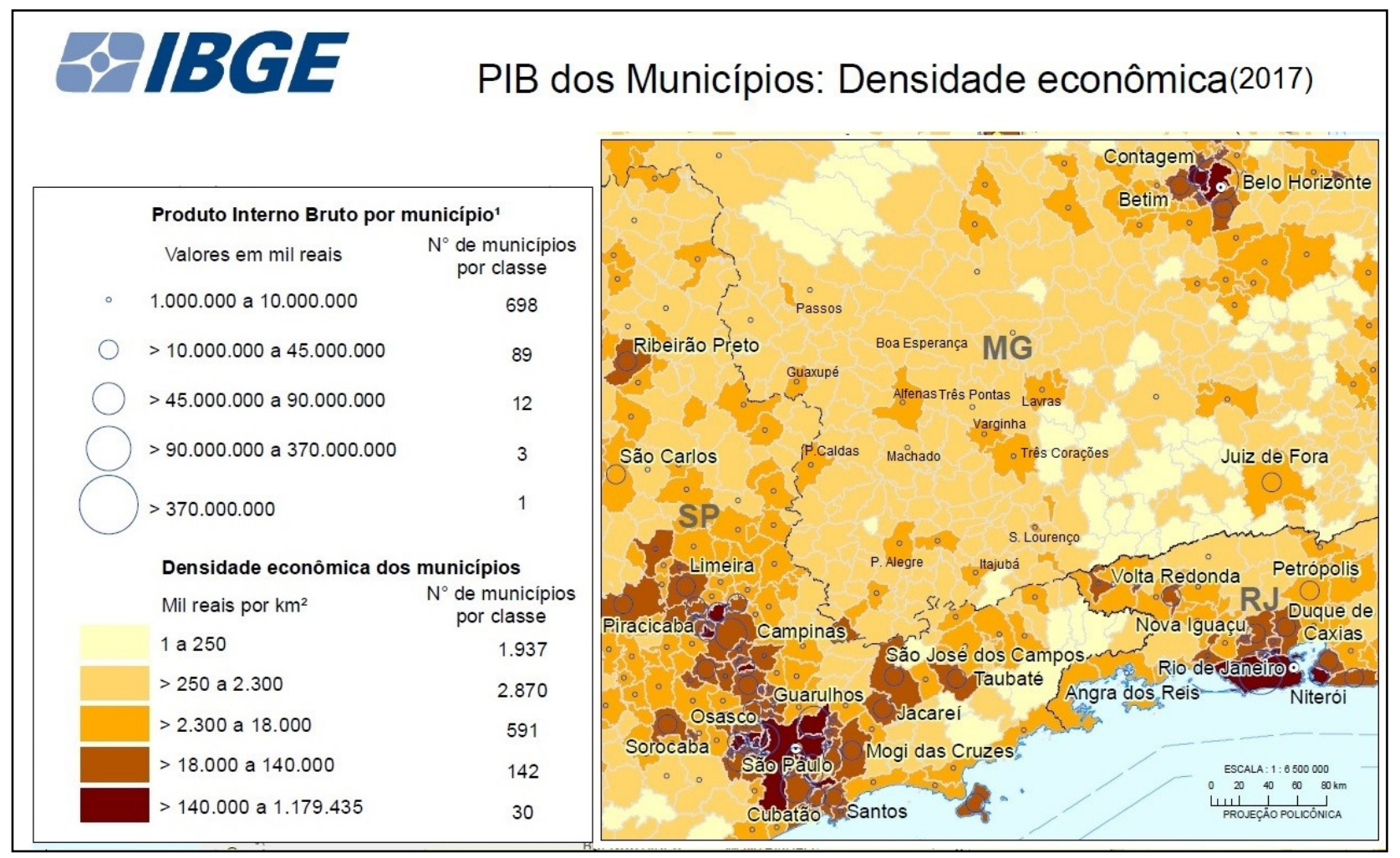

Figura 8 - Densidade econômica de municípios do Sul de Minas e regiões vizinhas, no ano de 2017.

Fonte: IBGE, 2020.

Tendo como parâmetro o mapa da figura 8, se percebe que ao redor do Sul de Minas, em especial no estado de São Paulo, há um grande número de municípios com alta densidade econômica, formando uma área que compreende a Região Metropolitana da capital, os eixos da AnhangueraBandeirantes (incluindo Campinas, Piracicaba, Jundiaí, Limeira, Rio Claro, e, um pouco adiante Ribeirão Preto), a Baixada Santista, Sorocaba, e o eixo da Dutra (São José dos Campos, Taubaté e Guaratinguetá). Neste último, apesar de perder intensidade de desenvolvimento no "fundo do Vale Paulista", volta a ganhar certa densidade econômica a partir de Resende (RJ), passando pelo arranjo 
populacional de Volta Redonda-Barra Mansa, em direção ao Grande Rio. Daí, em direção a Belo Horizonte, pela BR 040, possui algumas cidades importantes, em termos demográficos e produtivos, como Petrópolis e Três Rios (RJ), Juiz de Fora, Barbacena e Conselheiro Lafaiete (MG). A partir da região metropolitana de Belo Horizonte, a oeste, nos eixos da BR-262 e MG-050, estão as cidades de Divinópolis, Itaúna, Pará de Minas e Nova Serrana.

Em termos de posições na rede urbana, de acordo com o último REGIC (2018), estão neste sistema de cidades, a Grande Metrópole Nacional ${ }^{3}$ (Arranjo Populacional ${ }^{4}$ de São Paulo), uma Metrópole Nacional (A.P Rio de Janeiro), duas Metrópoles (A.P Belo Horizonte e A.P Campinas), uma Capital Regional ${ }^{5}$ A (A.P Ribeirão Preto), duas Capitais Regionais B (A.P Juiz de Fora e A.P São José dos Campos) e doze Capitais Regionais C (Figura 9).

No Sul de Minas, em termos de densidade econômica, como se pode observar no mapa da Figura 8, as cidades médias estão dentre as de maior importância, e o mesmo ocorre quanto a posição na rede urbana (Figura 9). Entretanto, devido a presença de diversas dentre as mais populosas e desenvolvidas metrópoles brasileiras, a influência externa continua bastante efetiva sobre o Sul de Minas, sendo que, pela classificação do REGIC de 2018, São Paulo polariza, juntamente com Belo Horizonte, todas as cidades médias, com exceção de Lavras, que é influenciada apenas pela capital mineira. A influência do Rio de Janeiro passou a ser secundária, e mais expressiva apenas à leste.

Varginha, Poços de Caldas e Pouso Alegre são as cidades com maior importância na rede urbana do Sul de Minas, estando na posição de Capital Regional C (TABELA 2). Se comparada a classificação anterior, Poços de Caldas subiu um nível na hierarquia, já que era um centro subregional A, situação esta em que permaneceram as cidades de Passos, Lavras e Alfenas. Por sua vez, Itajubá se manteve na classificação de centro sub-regional $\mathrm{B}$, polarizando basicamente municípios pouco populosos e de baixo dinamismo econômico localizados na Serra da Mantiqueira, como Delfim Moreira, Marmelópolis e Maria da Fé.

Em meio as cidades médias do Sul de Minas, Poços de Caldas apresentou aumento em sua centralidade, dentre outras razões por passar a polarizar, também, a região de influência de Alfenas, em que partilha a polarização com Varginha. Importante mencionar que nas classificações de 1966, 1978 e 1993, Poços de Caldas estava nas regiões de influências de Campinas em todos referidos estudos, e na de Ribeirão Preto em 1978; a partir da classificação de 2007 estava polarizada apenas

\footnotetext{
${ }^{3}$ Metrópoles - São os 15 principais centros urbanos, dos quais todas as cidades existentes no País recebem influência direta, seja de uma ou mais Metrópoles simultaneamente. A região de influência dessas centralidades é ampla e cobre toda a extensão territorial do País, com áreas de sobreposição em determinados contatos (IBGE: REGIC, 2018).

${ }^{4}$ Os critérios utilizados na identificação dos arranjos populacionais empregam a noção de integração, medida pelos movimentos pendulares para trabalho e estudo ou a contiguidade urbana, que assim sintetizam os vários processos envolvidos (IBGE: Arranjos Populacionais e Concentração Urbana no Brasil, 2015).

${ }^{5}$ São os centros urbanos com alta concentração de atividades de gestão, mas com alcance menor em termos de região de influência em comparação com as Metrópoles (IBGE: REGIC, 2018).
} 
pelas metrópoles (São Paulo e Belo Horizonte, sendo esta última apenas em 2018). "O fato de Poços de Caldas ter polarizado a cidade de Alfenas elevou expressivamente sua importância na rede urbana do Sul de Minas" (SILVA, 2021, p. 66). Com estas mudanças, Poços de Caldas, que tinha apenas um centro intermediário em sua rede (Andradas), passou a ter três (Andradas, Machado e a cidade média de Alfenas).

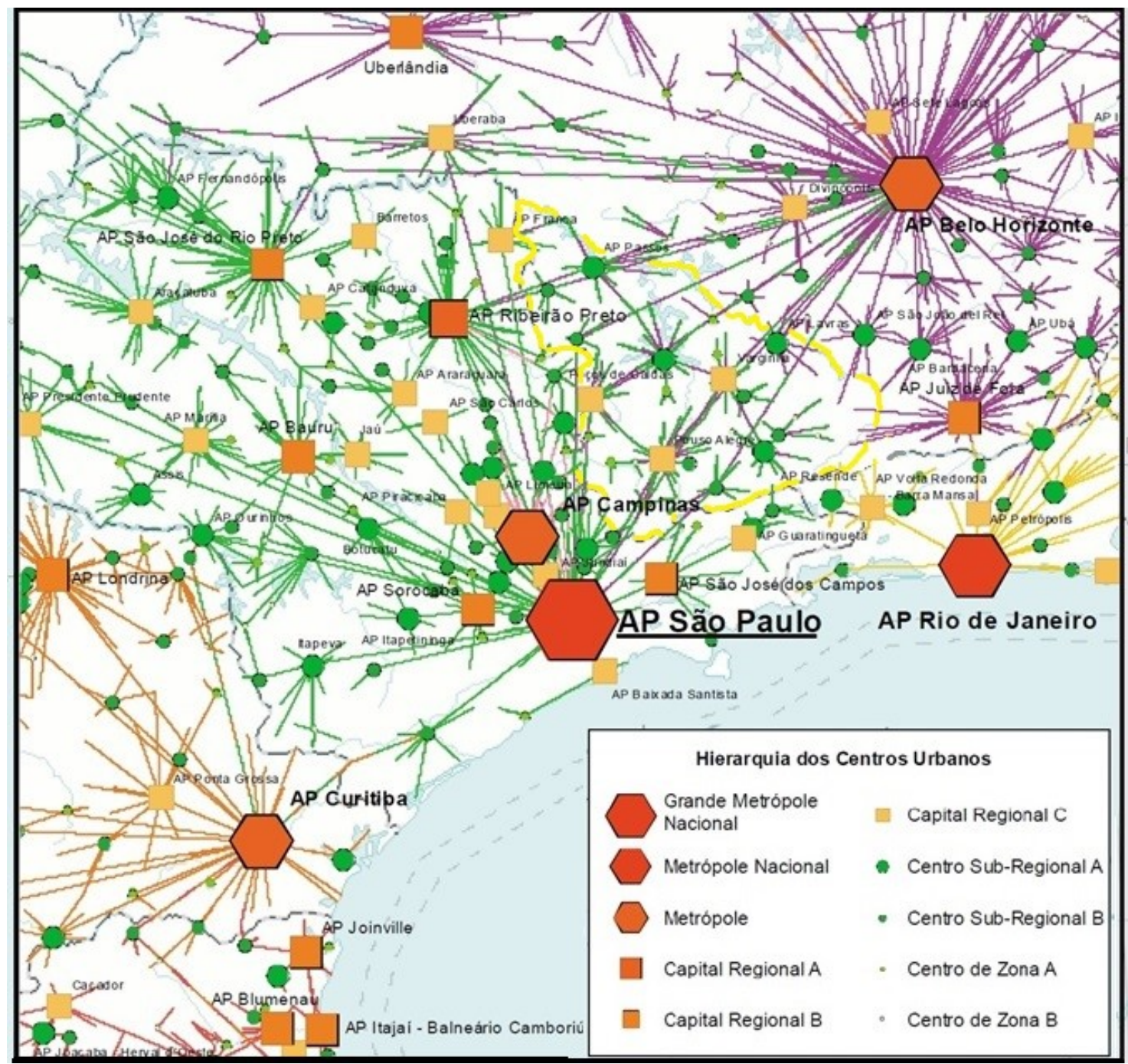

Figura 9 - As cidades sulmineiras na rede urbana nacional.

Fonte: IBGE (REGIC, 2007). Modificado pelos autores.

No caso de Passos, considerada um centro sub-regional A, se em 2007 era polarizada efetivamente apenas pela metrópole de Belo Horizonte, em 2018 voltou a ser polarizada por São Paulo, e agora também acrescida por Ribeirão Preto. Em 2007, parte da microrregião de Passos já era polarizada por Franca e Ribeirão Preto, mas, se naquela classificação apenas municípios pouco populosos estavam nesta situação (ANDRADE, 2014), na de 2018 Ribeirão Preto passou a polarizar, também, o importante município de São Sebastião do Paraíso, fazendo com que, na região de influência de Passos exista apenas um centro intermediário, Piumhi, que não faz parte da 
Macrorregião do Sul de Minas, mas sim da Macrorregião de Planejamento Centro-Oeste de Minas; na classificação anterior eram duas (Piumhi e São Sebastião do Paraíso).

Tabela 2: População e PIB das cidades médias do Sul de Minas e suas posições na rede urbana regional (2018).

\begin{tabular}{|c|c|c|c|c|}
\hline & $\begin{array}{l}\text { População } \\
\text { (2020) }\end{array}$ & $\begin{array}{c}\text { PIB (R\$ milhões) } \\
\text { (2018) }\end{array}$ & $\begin{array}{l}\text { Posição na rede } \\
\text { urbana }\end{array}$ & $\begin{array}{l}\text { Cidades com alguma centralidade no } \\
\text { interior das redes das cidades médias }\end{array}$ \\
\hline Varginha & 136.602 & $5.512,85$ & $\begin{array}{c}\text { Capital Regional } \\
\text { C }\end{array}$ & $\begin{array}{c}\text { Centro sub-regional A } \\
\text { Alfenas; São Lourenço } \\
\text { Centro sub-regional B } \\
\text { Três Corações; A.P Caxambu-Baependi } \\
\text { Centro de zona A } \\
\text { Três Pontas; Machado } \\
\text { Centro de zona B } \\
\text { Aiuruoca; Cruzília; Lambari }\end{array}$ \\
\hline $\begin{array}{l}\text { Pouso } \\
\text { Alegre }\end{array}$ & 152.549 & $7.619,10$ & $\begin{array}{l}\text { Capital Regional } \\
\text { C }\end{array}$ & $\begin{array}{l}\text { Centro sub-regional B } \\
\text { Santa Rita do Sapucaí; } \\
\text { Centro de zona A } \\
\text { A.P. Cambuí; Ouro Fino } \\
\text { Centro de zona B } \\
\text { Borda da Mata; Paraisópolis }\end{array}$ \\
\hline $\begin{array}{l}\text { Poços de } \\
\text { Caldas }\end{array}$ & 168.641 & $7.645,80$ & $\begin{array}{l}\text { Capital Regional } \\
\text { C }\end{array}$ & $\begin{array}{c}\text { Centro sub-regional A } \\
\text { Alfenas } \\
\text { Centro de zona A } \\
\text { Andradas; Machado }\end{array}$ \\
\hline A.P. Passos & 118.774 & $2.543,83$ & $\begin{array}{l}\text { Centro sub- } \\
\text { regional A }\end{array}$ & $\begin{array}{l}\text { Centro de zona B } \\
\text { Piumhi }\end{array}$ \\
\hline A.P. Lavras & 118.216 & $3.046,88$ & $\begin{array}{l}\text { Centro sub- } \\
\text { regional A }\end{array}$ & $\begin{array}{l}\text { Centro de zona B } \\
\text { Bom Sucesso }\end{array}$ \\
\hline Alfenas & 80.494 & $2.604,01$ & $\begin{array}{l}\text { Centro sub- } \\
\text { regional A }\end{array}$ & $\begin{array}{l}\text { Centro de zona A } \\
\text { Machado }\end{array}$ \\
\hline A.P. Itajubá & 118.150 & $3.244,56$ & $\begin{array}{l}\text { Centro sub- } \\
\text { regional B }\end{array}$ & 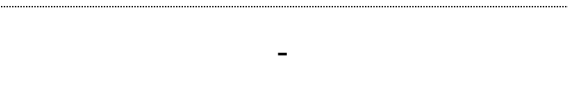 \\
\hline
\end{tabular}

Fonte: IBGE (REGIC, 1966, 1978, 1993, 2007). Organizado pelos autores.

Bem mais distante das fronteiras estaduais, Lavras, que manteve a condição de centro Subregional A, além da mesma posição na hierarquia urbana, apresenta, como Passos, um centro intermediário em sua região de influência (não tinha em 2007), Bom Sucesso, também pertencente a macrorregião Centro-Oeste. Nestes casos, Bom Sucesso e Piumhi, distantes de Divinópolis, a principal cidade desta referida macrorregião, estão em áreas onde a influência desta é baixa ou mesmo “inexistente” (MELLO, 2015), e acabam estando, assim, mais interligadas com as sulmineiras Passos e Lavras. Com a nova divisão do território brasileiro em Regiões Geográficas Imediatas e Regiões Geográficas Intermediárias ${ }^{6}$, pelo IBGE, em 2017, Bom Sucesso e Piumhi ficaram, respectivamente, nas Regiões Imediatas de Lavras e Passos, ambas na Região Intermediária de Varginha.

\footnotetext{
${ }^{6}$ Regiões Geográficas Imediatas têm na rede urbana o seu principal elemento de referência. Essas regiões são estruturas a partir de centros urbanos próximos para a satisfação das necessidades imediatas das populações. As Regiões Geográficas Intermediárias organizam o território, articulando as Regiões Geográficas Imediatas por meio de um polo de hierarquia
} 
Pouso Alegre, dentre as cidades médias do Sul de Minas foi a que apresentou maior crescimento populacional nas últimas décadas, e, de mero "ponto de passagem" da ferrovia, passou a apresentar uma maior importância econômica e na rede urbana regional, que fora potencializada com a implantação das rodovias, e mais recentemente com a duplicação da Fernão Dias (ANDRADE, 2014). Em 2007, já era uma Capital Regional C, posição que manteve em 2018. E, se por um lado, a oeste, sua rede perdeu a dinâmica cidade industrial de Jacutinga, que passou a ser polarizada por Campinas, e a sul a polarização sobre Extrema, município com maior PIB do Sul de Minas ${ }^{7}$ (IBGE, 2018), para Bragança Paulista (ambas partilhavam em 2007), por outro Pouso Alegre passou a polarizar Paraisópolis, antes pertencente a região de influência de Itajubá.

E, em uma pequena distância de 60 quilômetros que separam estas duas cidades médias, que recorrentemente são associadas como uma "aglomeração urbana e/ou um sistema integrado de cidades" (ANDRADE, 2014), estão os maiores contrastes entre as dinâmicas que ocorreram nos últimos sessenta anos na rede urbana regional. Pois, Pouso Alegre, agora polariza cinco centros intermediários, enquanto Itajubá não polariza nenhum (era um, Paraisópolis, em 2007), e está na menor posição hierárquica entre as cidades médias sulmineiras (IBGE: Regic, 2018); ademais, Pouso Alegre exerce significativa centralidade sobre a região de influência de Itajubá, sendo que, dos treze municípios desta, nove eram, também, da área de influência pousoalegrense (ANDRADE, 2017).

Varginha e Pouso Alegre são as cidades principais de suas respectivas Regiões Geográficas Intermediárias. São estas as duas regiões do Sul de Minas, sendo que Poços de Caldas, mesmo considerada uma Capital Regional C, por este critério está inserida na região de Pouso Alegre. Entretanto, como anteriormente mencionado, por sua posição geográfica, mais distante das fronteiras estaduais, e da concorrência com os dinâmicos centros urbanos das redes paulista e fluminense, e mesmo de importantes cidades mineiras, tais como Juiz de Fora, Divinópolis e Belo Horizonte, Varginha não só manteve sua posição de Capital Regional C, como continua tendo o maior número de centros intermediários (nove) dentre as regiões de influência capitaneadas pelas cidades médias do Sul de Minas, que conta, inclusive, com quatro centros sub-regionais, sendo dois "A", Alfenas e o A.P. São Lourenço, e dois "B” Três Corações e o A.P Caxambu-Baependi.

São Lourenço que, mesmo por questões demográficas não possa ser considerada uma cidade média (46.602 habitantes, IBGE:2020 ${ }^{8}$ ), ampliou sua importância na rede urbana regional, e passou

\footnotetext{
superior diferenciado a partir dos fluxos de gestão privado e público e da existência de funções urbanas de maior complexidade. (IBGE: O recorte das Regiões Geográficas Imediatas e Intermediárias de 2017).

${ }^{7}$ Extrema, localizada na fronteira com o estado de São Paulo, e às margens da Fernão Dias, possui 36951 habitantes (IBGE, 2020), PIB de R\$ 9,523 bilhões (2018), e, de acordo com OLIVEIRA (2018), recebeu grandes investimentos industriais nas últimas décadas, fazendo com que sua economia tenha crescido rapidamente, assim como sua população. ${ }^{8}$ Somando Soledade de Minas (6.189 habitantes), que forma o A.P São Lourenço, a população é de 52.791. Também é viável incluir, na aglomeração, o município de Carmo de Minas, com 14.859 habitantes (IBGE, 2020), uma vez que este é praticamente conurbado com São Lourenço, e é considerado de "alta integração com o arranjo populacional” (IBGE: Arranjos Populacionais e Concentração Urbana no Brasil, 2015). Somando, assim, 67.650 habitantes.
} 
a ser um centro sub-regional A, e isso se deu pela consolidação de sua polarização sobre um conjunto de cidades, com certa proximidade geográfica e relativo desenvolvimento econômico, em que mesclam atividades turísticas e agropecuárias. E, além de São Lourenço, há mais quatro cidades com posições intermediárias na rede, A.P. Caxambu-Baependi, Lambari, Cruzília e Aiuruoca, sendo as primeiras consideravelmente integradas com Varginha, e as duas últimas, apesar de também fazer parte da região de influência varginhense, já estão em uma área com menores densidades econômicas e demográficas, e com históricas influências do Rio de Janeiro e de capitais regionais como Juiz de Fora e Volta Redonda.

Alfenas, também um centro sub-regional A, voltou a ser polarizada por Varginha, como nas classificações de 1966 e 1978, e constitui importante centro de atração em decorrência de suas estruturas de saúde e educação, além de sua significância comercial; na região de Alfenas, nesta última classificação polarizada tanto por Varginha quanto por Poços de Caldas, está o centro intermediário de Machado.

Em seu entorno imediato, e fazendo parte da região de influência de Varginha, estão duas cidades dentre as mais populosas e produtivas economicamente do Sul de Minas: Três Corações e Três Pontas; estas, juntamente com Elói Mendes, formam um sistema de cidades, que tem Varginha em posições geográficas e funcionais centrais, que possui 301.894 habitantes e Produto Interno Bruto de 9,68 bilhões de reais (IBGE, 2020; 201899). Tal condição, favorece a existência de diversas estruturas comerciais e de prestações de serviços em Varginha, que atendem aos moradores do município, mas também dos habitantes dos espaços urbanos e rurais de sua área de influência.

\section{A CIDADE MÉdIA DE VARGINHA E AS NOVAS CENTRALIDADES}

Locais onde geralmente ocorreram a fundação e o início da formação de uma cidade, as áreas centrais frequentemente são (ou foram) as regiões mais valorizadas, em termos econômico e de status social, por conciliar os espaços para práticas diversas, como comércio, administração pública, prestação de serviços, recreação, religião, atividades artístico-culturais, dentre outras, e por abrigar as construções com importantes representatividades funcionais e simbólicas, como templos religiosos, edifícios públicos, agências bancárias, clubes, espaços culturais, e mesmo as residências das elites.

Em Varginha, no centro da cidade, localizado em uma área mais elevada em relação ao entorno, foram implantadas, desde o início da urbanização, a Igreja Matriz e a Câmara Municipal, enquanto em direção ao fundo de vale encontra-se a antiga Estação Ferroviária (Figura 10). E, nas

\footnotetext{
${ }^{9}$ Três Corações possui 80.032 habitantes, Três Pontas 56.940 e Elói Mendes 28.320 (IBGE, 2020); quanto ao PIB, o de Três Corações é de R\$ 2,31 bilhões, de Três Pontas R\$ 1,35 bilhão, e Elói Mendes R\$ 0,511 bilhão (IBGE, 2018). As informações referentes a Varginha estão na tabela 2.
} 
proximidades destes locais foram se desenvolvendo estruturas voltadas ao comércio, as prestações de serviços, as práticas artístico-culturais, dentre outras.

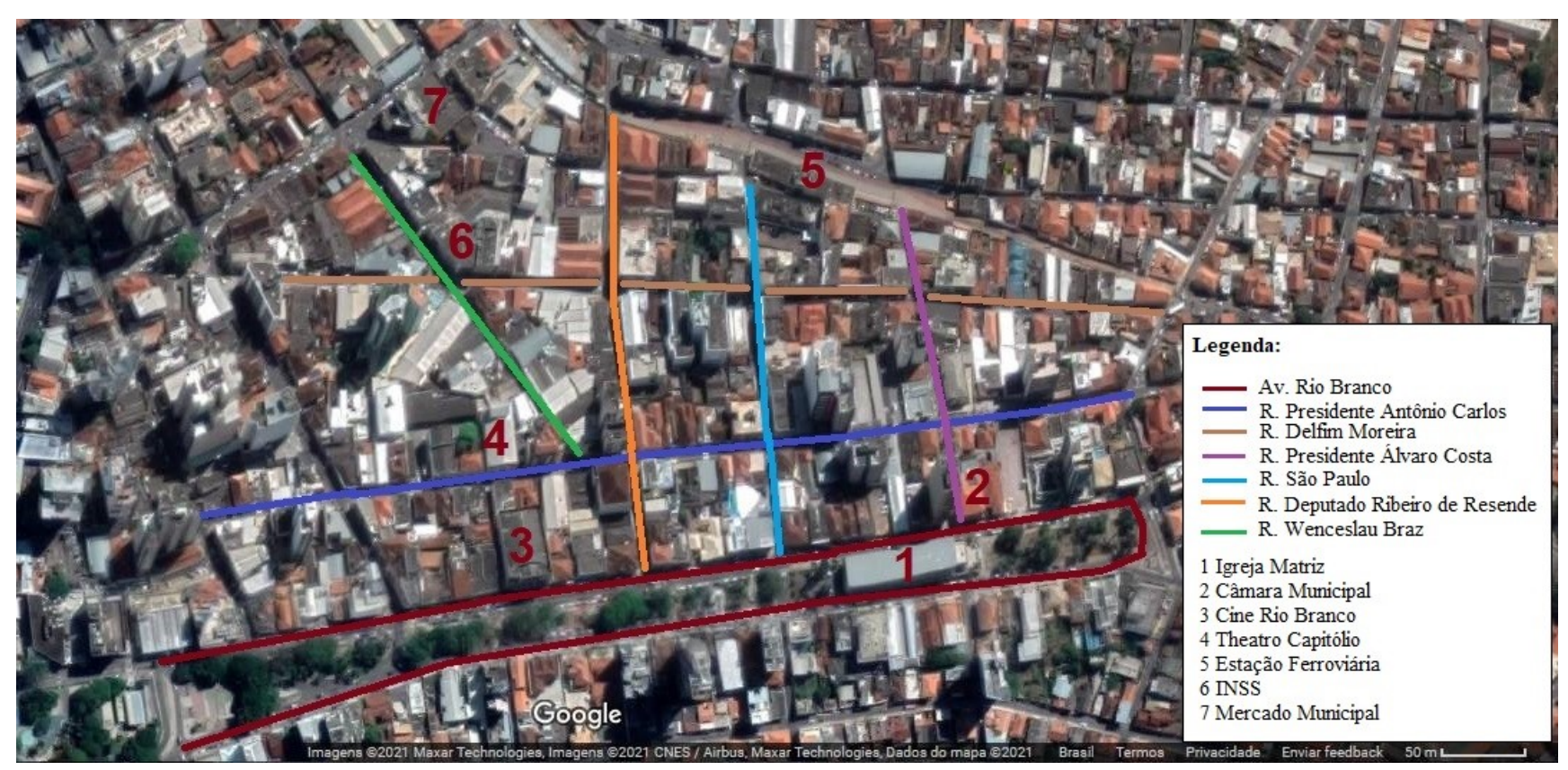

Figura 10 - Principais ruas, avenidas e estabelecimentos do centro da cidade de Varginha.

Fonte: Google Earth (Organizado pelos autores).

A Avenida Rio Branco, bem como as principais ruas do centro da cidade, demonstradas pela figura 10, possuem diferentes estruturas do setor terciário, que revelam sua importância secular na cidade. A região próxima à Estação Ferroviária, desde sua fundação no período oitocentista, movimenta a cidade com fluxo de pessoas, o que torna o trecho desde então, favorável ao aparecimento dos primeiros comércios básicos e serviços, como a primeira instituição bancária na cidade (VEIGA, 1874, 1884; SALES, 2003; FERREIRA, 2017). Estes elementos, em proximidade como a Câmara Municipal, revelam, portanto, desde a fundação da cidade, o intuito inicial do agrupamento do poder público e econômico no centro da cidade.

$\mathrm{Na}$ atualidade, as ruas que interligam a região da Estação Ferroviária até a Avenida Rio Branco, são portadoras de diversos estabelecimentos comerciais, dos mais diversos portes, e também edificações com diversas finalidades, dentre elas moradias; enquanto a avenida é marcada pela expressiva presença de instituições bancárias, e, por sua histórica importância funcional e simbólica, passou por diversas obras para melhorias paisagísticas.

Assim como ocorreu em outras cidades médias brasileiras e do Sul de Minas, Varginha apresentou significativo crescimento populacional, que refletiu na expansão de sua área urbana, no período entre 1980 e 2021 (Figura 11). 


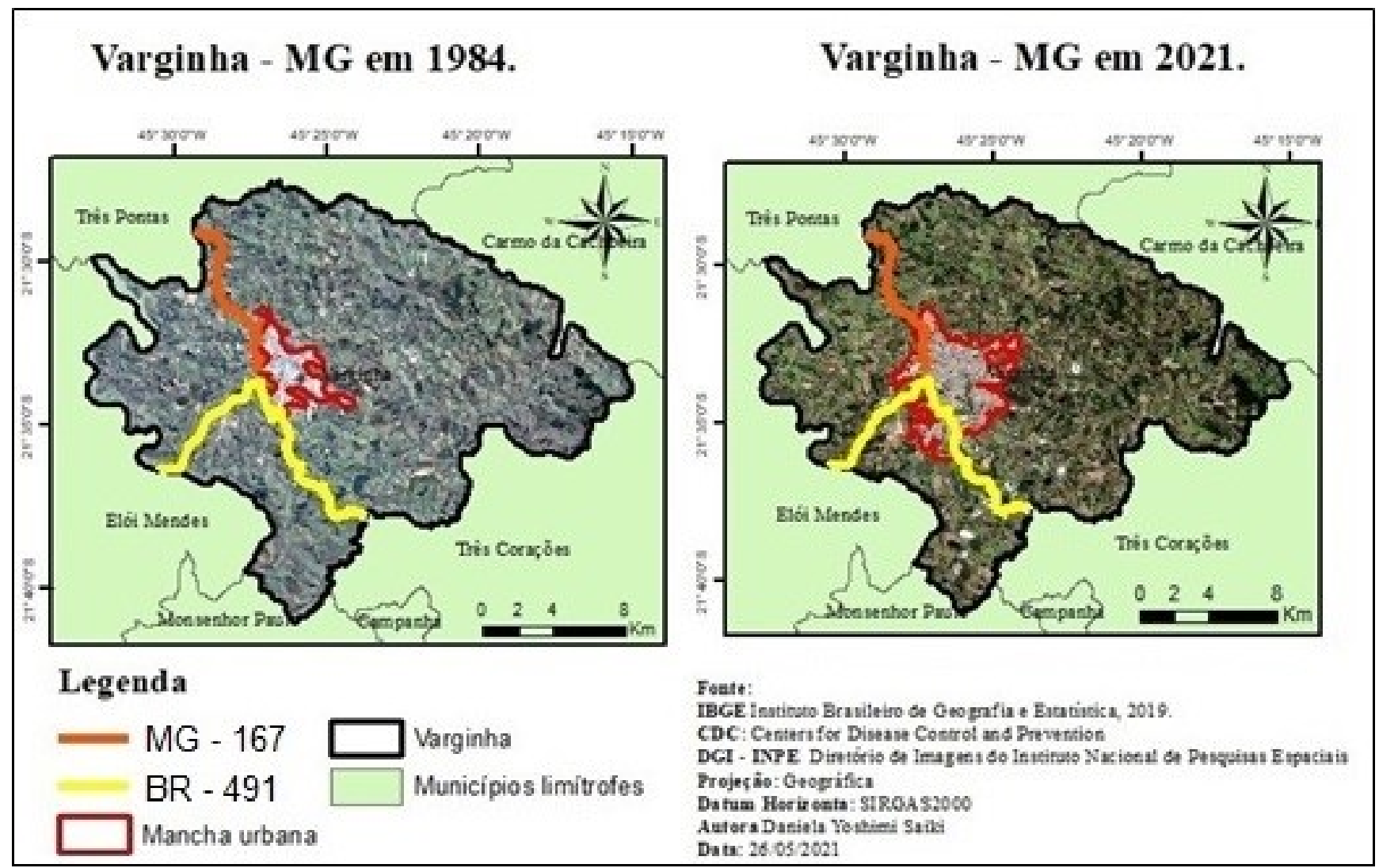

Figura 11 - Mapa de expansão urbana de Varginha, entre os anos de 1984 e 2021.

Fonte: Instituto Brasileiro de Geografia e Estatística.

Entre 1980 e 2021, condicionantes econômicos, demográficos, políticos e socioculturais favoreceram novas dinâmicas espaciais, que, dentre outras coisas, interferiram na expansão urbana de Varginha, assim como na maior fragmentação do espaço. A presença de importantes rodovias, aliada com a influência de Varginha em um amplo setor da região do Sul de Minas, colaboraram efetivamente para a formação e consolidação de novas áreas de comércio e de prestações de serviços no espaço urbano local. A atração de pessoas provenientes de municípios da região favorece não só a abertura e expansão de estabelecimentos, mas, também, a apropriação de áreas voltadas às funções terciárias na cidade, formando novas centralidades com atratividades locais e regionais.

Os subcentros e as novas centralidades são formados nas cidades, devido a dispersão geográfica das atividades econômicas, mas também, associadas a toda uma conjuntura espacial que a cidade adquire, como a construção de novos bairros residenciais, para atender a demanda de moradores, inclusive migrantes atraídos pelas oportunidades profissionais que a cidade proporciona, mas, também, devido as demandas de pessoas, por produtos e serviços, provenientes de outros municípios polarizados por Varginha. Essa “dispersão espacial das atividades econômicas contribui para uma procura de novas formas de centralização territorial” (RODRIGUES, FARIA, 2017, p. 03).

Sendo um ponto de convergência de pessoas, informações e dinheiro, as centralidades tornam-se dispersas do centro geográfico e formam novos subcentros; que, por sua vez, podem ser 
gerados por shoppings, eixos comerciais, centros especializados etc. (PEDROSO, 2007, SPOSITO, 2013). As novas centralidades na cidade de Varginha são demonstradas na figura 12.

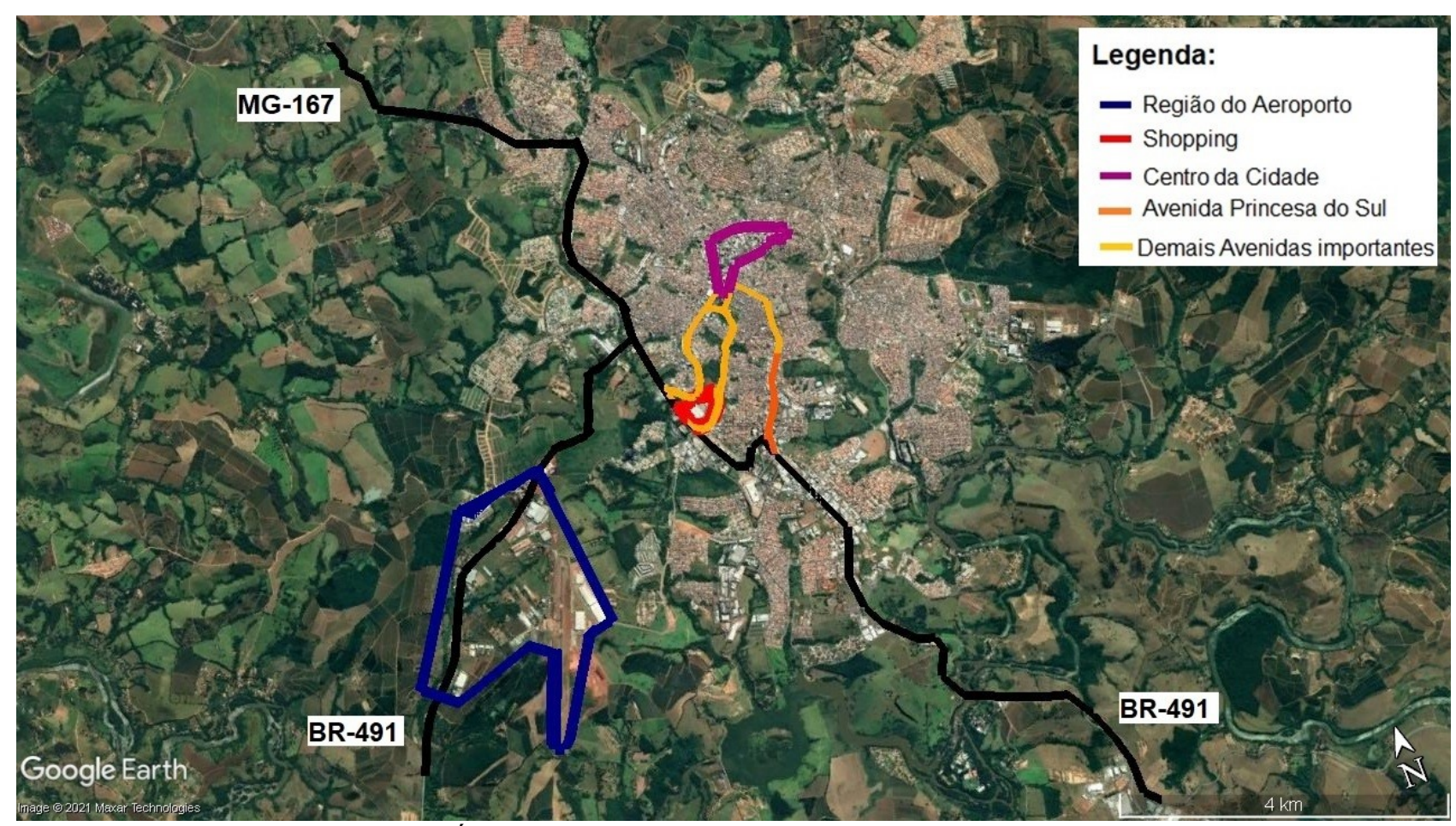

Figura 12 - Área central e importantes vias e centralidades de Varginha.

Fonte: Google Earth (Organizado e modificado pelos autores).

A facilidade de acesso por avenidas, que são diretamente interligadas com a MG-167 e a BR-491, é um dos fatores que possibilita a ampliação do setor terciário em áreas externas ao centro da cidade, formando consequentemente novas centralidades. "Na escala intraurbana, o fenômeno da 'dispersão urbana' está alterando a morfologia urbana tradicional, gerando novas centralidades e novas periferias" (SOARES, 2006, p. 01). São três as principais áreas no espaço intraurbano de Varginha, que possuem centralidades relevantes para pessoas do município e da região: a Avenida Princesa do Sul, a região do Aeroporto e o Via Café Garden Shopping.

A Avenida Princesa do Sul, que possui ligação direta com o centro da cidade ${ }^{10}$, e sua extensão no trecho urbano da BR-491, apresenta forte presença de estabelecimentos de grande porte, e de atratividade regional, do setor terciário. $\mathrm{Na}$ área há um significativo adensamento de concessionárias de veículos (Fiat, Ford, Caoa Chery, Chevrolet, Hyundai, Honda, Nissan, Renault, Toyota e Volkswagen), bem como aloca dois grandes supermercados (Bretas e o Alvorada ${ }^{11}$ ), filiais de agências bancárias da Caixa Econômica Federal, Bradesco e Santander, e estabelecimentos do setor terciário, como a sede do IPD Laboratórios e Trevisan Móveis. Ainda, ao longo da Avenida

\footnotetext{
${ }^{10}$ Em ligação com a Avenida Francisco Navarra.

${ }^{11}$ Ambos possuem mais de um estabelecimento pela cidade.
} 
Princesa do Sul e ruas adjacentes a mesma, se encontram órgãos públicos, tais como Polícia Federal, Superintendência Regional da Fazenda, Justiça Federal.

Localizada na zona sudoeste da cidade, a região do Aeroporto encontra-se acompanhada de estruturas importantes para a cidade, e mesmo para a região, como Porto Seco, Centro Universitário do Sul de Minas (UNIS), algumas indústrias, empresas de beneficiamento e exportação de café, dentre outras estruturas que favoreceram a expansão urbana ${ }^{12}$ da cidade nesta direção, e também a constituição de novas centralidades. Às margens da rodovia BR-491, tem fácil acesso às pessoas e mercadorias provenientes de municípios da região.

O Via Café Garden Shopping de Varginha foi inaugurado no ano de 2016, em uma localização próxima ao centro e às margens da BR-491 e, desde então, reordena as centralidades varginhenses, bem como as novas dinâmicas comerciais e socioculturais. Os shoppings centers são pontos de centralidades desde os anos sessenta, com a instalação do primeiro no país (Iguatemi, em São Paulo), e, vistos como "signos e ícones da modernidade e desenvolvimento", inicialmente se proliferaram nas metrópoles para, posteriormente, serem instalados nas cidades médias (OLIVEIRA JÚNIOR, 2011). Sendo assim, mesmo que tardiamente, em Varginha também incide o processo de reordenamento de centralidades, onde os espaços de consumos e entretenimentos que nascem descentralizados no município, pertencentes ao shopping center, apresentarão "uma disputa" em relação ao centro da cidade quanto às suas atratividades.

Os estabelecimentos presentes no shopping em Varginha, são os mais diversos, desde redes de fast food (MC Donald's, Burguer King, Bobs, Spoletto), lojas de roupas e calçados (Renner, Riachuelo, World Tênis) e de variedades (1 a 99 e Lojas Americanas), que, ao serem implantados, constituíram "novidades" na cidade e mesmo na sua região de influência. Mas há também comércios e serviços que se deslocaram desde o centro da cidade, ou abriram uma filial no shopping, como são os casos da Ariane Joias, Agência da SICOOB, Arezzo, Cacau Show, Calçados Bomfim, Game Power, Karina Casa e Conforto, Lojas Havaianas, Lojas Edmil, Ótica Chilli Beans, O Boticário, Track \& Field, dentre outras, bem como a academia Body Health, que possuí uma filial na Avenida Princesa do Sul e outra no shopping.

Para além das atividades comerciais, o Via Café Garden Shopping aloca as únicas salas de cinema da cidade na atualidade, fortalecendo sua atratividade neste setor de entretenimento, antes presente apenas na área central. Por sua vez, a migração da Unidade de Pronto Atendimento (UAI), que é o órgão onde se retira documentos pessoais, inclusive passaportes, para o shopping, é outra estratégia que favoreceu o aumento de suas centralidades, já que moradores do município e da região,

\footnotetext{
${ }^{12}$ Empreendimentos do setor imobiliário.
} 
necessitam entrar no shopping para a emissão de tais documentos, o que, por vezes, podem incentivar o consumo de produtos, serviços e entretenimento nos estabelecimentos locais.

Varginha, portanto, apresenta uma reestruturação das centralidades de seu espaço intraurbano e nas relações entre cidades de sua região de influência. Trata-se de um "processo contínuo de estruturação-desestruturação-reestruturação das estruturas urbanas" (OLIVEIRA JÚNIOR, 2008, p. 73), que é visualizado principalmente em proximidades com os shoppings, onde as verticalizações, novos empreendimentos e remodelamento da paisagem urbana tomam forma no entorno (SOARES, 2006, SPOSITO, 2011), como começa a ocorrer, em Varginha, com o Via Café Garden Shopping.

Para favorecer a acessibilidade foi implantada, na última década, uma avenida que interliga a BR-491, nas imediações do shopping, com outros setores da cidade de Varginha, o que motivará ainda mais a construção de residências, mas também de novas estruturas voltadas ao setor terciário. Nas novas centralidades há importantes articulações com os diversos setores da cidade média de Varginha, mas também suas localizações e funcionalidades favorecem a atratividade e a acessibilidade para os moradores da sua área de influência, em especial os residentes em municípios próximos e expressivamente populosos, como Três Corações, Três Pontas e Elói Mendes, mas, mesmo que em menor frequência, também de outras cidades médias, como Lavras e Alfenas.

\section{CONSIDERAÇÕES FINAIS}

As influências externas (importantes metrópoles e "grandes cidades médias"), os sistemas de transportes, a extensão territorial e a falta de efetiva integração regional, não favoreceram a presença de um centro urbano que polarize todo o Sul de Minas. Devido a isso há uma rede urbana descentralizada, onde cidades médias como Varginha, Poços de Caldas, Pouso Alegre, Passos, Itajubá, Lavras e Alfenas exercem polarizações em seus entornos, ao mesmo tempo em que o Sul de Minas recebe importantes e duradouras influências de áreas externas.

A posição geográfica de Varginha, mais "central" no conjunto da região sulmineira, associada com as estruturas existentes no município, fazem com que a cidade tenha sido classificada nas mais altas posições nos estudos sobre a rede urbana regional. Isto favorece a afluência de migrantes, que passam a residir no município pelas ofertas profissionais, educacionais e mesmo socioculturais. Ao mesmo tempo, como ocorre em outras cidades médias brasileiras, Varginha passa a alocar "modernidades", como no setor de comércio (concessionárias de veículos de diversas marcas, redes de fast food...), e de entretenimento (futebol, a exemplo do Boa Esporte, que disputa importantes torneios; e festivais musicais, como o Roça'n Roll), e, mais recentemente o Via Café Garden Shopping, e estas estruturas e eventos atraem pessoas de municípios de sua área de influência. 
Estas novas dinâmicas socioespaciais exercem influências na produção do espaço urbano de Varginha, e nas ações de seus agentes sociais. O Estado, por meio da implantação de vias, os donos dos meios de produção, através da criação de grandes estruturas comerciais, de prestações de serviços ou de entretenimento, acabam, direta e indiretamente, beneficiando os proprietários fundiários e os agentes imobiliários, que promovem novos usos e valores mercantis ao solo urbano. Devido a essas mudanças, o centro que historicamente tinha o protagonismo em termos de atratividades para moradores do município, mas também de cidades e espaços rurais de sua área de influência, agora já começa a ser ameaçado por outras áreas, dentre elas os subcentros e especialmente as novas centralidades, a exemplo do shopping center. Com isso há uma reestruturação no espaço intraurbano de Varginha, com a maior seletividade do território, seja para as atividades econômicas, mas também para moradias, colaborando, assim, para aumentar as desigualdades socioespaciais.

\section{REFERÊNCIAS}

ALviM, A. M. M. Cidades médias em Minas Gerais e no Chile: um estudo comparativo entre Formiga e Ovalle. 1998. 197 f. Dissertação (Mestrado em Tratamento da Informação Espacial) Pontifícia Universidade Católica de Minas Gerais, Belo Horizonte, 1998.

AMORIM FILHO, O. B. Cidades médias e a organização do espaço no Brasil. Revista Geografia e Ensino, v. 2, n.5, p. 5-34, 1984.

. A evolução dos Estudos sobre Cidades Médias em Minas Gerais. In: SATHLER, D.; AMORIM FILHO, O. B.; VARAJÃO, G. F. D. C. (Org.). Cidades Médias: Bases teóricas e estudos aplicados à Diamantina. Belo Horizonte: Fino Traço, 2015. p. 9-83.

AMORIM FILHO, O. B.; RIGOTTI, J. I. R.; CAMPOS, J. Os níveis hierárquicos das cidades médias de Minas Gerais. Revista Ra'ega, n. 13, p. 7-18, 2007.

ANDRADE, A. C. Paisagem e qualidade de vida em localidades turísticas: o caso de Poços de Caldas (MG). 2005. 188 f. Dissertação (Mestrado em Geografia) - Universidade Estadual Paulista, Rio Claro, 2005.

. Pouso Alegre (MG): Expansão urbana e as dinâmicas socioespaciais em uma cidade média. 2014. 299 f. Tese (Doutorado em Geografia) - Universidade Estadual Paulista, Rio Claro, 2014.

Cidade média e sua rede urbana: as inter-relações entre Pouso Alegre (MG) e os municípios de sua área de influência. Acta Geográfica, v. 11, n. 27, p. 126-148, 2017.

ANDRADE, A. C.; MARQUES NETO, R.; BACHA, R. M. C.; FERREIRA, E. R. Do turismo das águas minerais ao turismo em áreas rurais: a microrregião de São Lourenço (MG). Geo UERJ, v. 16, p. 57-78, 2014.

AZEVEDO, A. O Brasil e suas regiões. Rio de Janeiro: Cia Editora Nacional, 1971. 391p. 
BATISTA, F. A.; BARBOSA, L. S.; GODOY, M. M. Transportes, modernização e formação regional: subsídios a história da era ferroviária em Minas Gerais (1870-1940). Belo Horizonte: CEDEPLAR, 2012. 40p.

BERNARDES, L. M. C. Enciclopédia dos municípios brasileiros: Grande Região Leste - o planalto. Rio de Janeiro: IBGE, 1963. 331p.

CASTILHO, F. F. A. As Estradas de Ferro do Sul de Minas. Heera, v. 7, p. 43-63, 2012.

CONTE, C. H. Cidades Médias: Discutindo o Tema. Sociedade e Território, v. 25, p. 45-61, 2013.

CORRÊA, R. L. Construindo o Conceito de Cidade Média. In: SPOSITO, M. E. B. (Org.). Cidades Médias: Espaço em transição. São Paulo: Expressão Popular, 2007. p. 23-34.

COSTA, E. M. Cidades médias: Contribuições para a sua definição. Finisterra, v. 37, n. 74, p.101$128,2002$.

DEFFONTAINES, P. Como se constituiu no Brasil a rede de cidades I. Boletim Geográfico, v. 2, n. 14, p. 141-148, 1944.

FERREIRA, N. S. A Formação da Cidade de Varginha/MG e a Chegada dos Serviços Urbanos (18821920). Cultura Histórica \& Patrimônio, v. 4, n. 1, p. 120-145. 2017.

FERREIRA, N. S. A cidade de Varginha (MG) Atividades Econômicas e a chegada da Estrada de Ferro (1882-1920). In: SIMPÓSIO NACIONAL DE HISTÓRIA, 29., 2017, Brasília. Anais... Brasília: ANPUH, 2017. p. 01-15.

FURTADO, C. Formação econômica do Brasil. São Paulo: Cia. Editora Nacional, 1976. 248p.

GEIGER, P. P; DAVIDOVICH, F. Aspectos do fato urbano no Brasil. Revista Brasileira de Geografia, v. 23, n. 2, p. 263-363, 1961.

GIOVANINI, R. R.; MATOS, R. E. S. Geohistória Econômica da Zona da Mata Mineira. In: SEMINÁRIO SOBRE A ECONOMIA MINEIRA, 11., 2004. Diamantina. Anais... Diamantina: CEDEPLAR, 2004. p. 1-25.

GOVERnO DE MINAS GERAIS. Caderno Regional do Sul de Minas. Belo Horizonte, 2014. $235 p$.

IBGE - INSTITUTO BRASILEIRO DE GEOGRAFIA E ESTATÍSTICA. Arranjos Populacionais e Concentração Urbana no Brasil. Rio de Janeiro, 2015. 167p.

IBGE - INSTITUTO BRASILEIRO DE GEOGRAFIA E ESTATÍSTICA. O recorte das Regiões Geográficas Imediatas e Intermediárias de 2017. Rio de Janeiro, 2017. 34p.

IBGE - INSTITUTO BRASILEIRO DE GEOGRAFIA E ESTATÍSTICA. Regiões de Influência das Cidades, 2018. Rio de Janeiro, 2020. 196p.

IPEA; IBGE; UNICAMP. Caracterização atual e tendências da rede urbana do Brasil. Brasília, 2001. 397p. 
MATOS, R. E. S. A expansão demográfica em algumas das principais cidades mineiras. In: ENCONTRO NACIONAL DE ESTUDOS POPULACIONAIS, 6., 1988, Belo Horizonte. Anais... Belo Horizonte: ABEP, 1988. p. 221-248.

Migração e urbanização no Brasil. Geografias, v. 8 n. 1, p. 7-23, 2012.

MELLO, N. C. S. Divinópolis: uma cidade média na região Perimetropolitana de Belo Horizonte. 2015. 297 f. Tese (Doutorado em Tratamento da Informação Espacial) - Pontifícia Universidade Católica de Minas Gerais, Belo Horizonte, 2015.

MELLO FILHO, M. S. B.; SANTOS FILHO, J. M. População e geografia econômica: a conformação da população no espaço em Minas Gerais, no século XIX. In: ENCONTRO NACIONAL DE ESTUDOS DA POPULAÇÃO, 14., 2006, Caxambu. Anais... Caxambu: ABEP, 2006. p. 1-20.

OLIVEIRA, E. M. A implantação de grandes indústrias de capitais nacionais e internacionais na cidade pequena de Extrema (MG): processos, fatores e agentes. 2018. $294 \mathrm{f}$. Tese (Doutorado em Geografia) - Universidade Estadual Paulista, Rio Claro, 2018.

OLIVEIRA JÚNIOR, G. Novas expressões de centralidade e (re)produção do espaço urbano em Cidades Médias: O Jequitibá Plaza Shopping em Itabuna-BA. 2008. 449 f. Dissertação (Mestrado em Geografia) - Universidade de Brasília, Brasília, 2008.

OLIVEIRA JÚNIOR, G. Centro e novas expressões de centralidade em cidades médias: as respostas do centro tradicional da redefinição do velho. Boletim Geográfico, v. 29, n. 1, p. 67-75, 2011.

PAIVA, C. A. População e economia nas Minas Gerais do século XIX. 1996. 254 f. Tese (Doutorado em História Social) - Universidade de São Paulo, São Paulo, 1996.

PEDROSO, F. O centro de Campinas (SP) - usos e transformações. 2007. 122 f. Dissertação (Mestrado em Geografia) - Universidade Estadual de Campinas, Campinas, 2007.

RODARTE, M. M. S. O caso das minas que não se esgotaram: a pertinácia do antigo núcleo central minerador na expansão da malha urbana da Minas Gerais oitocentista. 1999. 179 f. Dissertação (Mestrado em Economia) - Universidade Federal de Minas Gerais, Belo Horizonte, 1999.

RODRIGUES, H. R.; FARIA, T. C. A. O reflexo da reestruturação produtiva nas cidades médias: o caso de Varginha/MG. In: ENCONTRO NACIONAL DA ASSOCIAÇÃO NACIONAL DE PÓSGRADUAÇÃO E PESQUISA EM PLANEJAMENTO URBANO E REGIONAL, 17., 2017, São Paulo. Anais... São Paulo: ANPUR, 2017. p. 01-19.

SAES, A. M.; COSENTINO, D. V.; GAMBI, T. F. R. Sul de Minas em transição: opção por uma regionalização como ponto de partida. In: SAES, A. M.; MARTINS, M. L. (Orgs.). Sul de Minas em transição: a formação do capitalismo na passagem para o século XX. Bauru: EDUSC, 2012. p. 1336.

SALES, J. R. Espírito Santo da Varginha (MG) - 1763-1920. Varginha: Gráfica Editora Sul Mineira, 2003. 381p.

SANTOS, M. A urbanização brasileira. São Paulo: Edusp, 2005. 184p. 
SILVA, E. A. (Re)produção do espaço urbano e segregação socioespacial em Poços de Caldas, Minas Gerais. 2021. 211 f. Dissertação (Mestrado em Geografia) - Universidade Federal de Alfenas, Alfenas, 2021.

SILVA, M. P. Tem café nesse trem? As ferrovias do Sul de Minas Gerais (1874 - 1910). In: SAES, A. M.; MARTINS, M. L. (Orgs.). Sul de Minas em transição: a formação do capitalismo na passagem para o século XX. Bauru: Edusc, 2012. p. 177-208.

SILVEIRA, M. L. Globalização, Trabalho, Cidades Médias. Geo UERJ, n. 11, p. 11-17, 2002.

SOARES, B. R. Repensando as cidades médias brasileiras no contexto da globalização. Formação, n. 6, p. 55-63, 1999.

SOARES, P. R. Cidades médias e aglomerações urbanas: a nova organização do espaço regional no Sul do Brasil. In: SPOSITO, E. S.; SPOSITO, M. E. B.; SOBARZO, O. (Orgs.). Cidades médias: produção do espaço urbano e regional. São Paulo: Expressão Popular, 2006. p. 347-364.

SPOSITO, M. E. B. A produção do espaço urbano: escalas, diferenças e desigualdades socioespaciais. In: CARLOS, A. F. A.; SOUZA, M. L; SPOSITO, M. E. B. (Org.). A produção do espaço urbano: agentes e processos, escalas e desafios. São Paulo: Contexto, 2011. p. 123-145.

SPOSITO, M. E. B. Centro e Centralidades no Brasil. In: FERNANDES, J. A. V. R.; SPOSITO, M. E. B. (Orgs.). A nova vida do velho centro. Lisboa: Centro de Estudos Geográficos e Ordenamento do território, 2013. p. 45-62.

STÈFANI, J. Sul de Minas na primeira metade do século dezenove: potencial de centralidade urbana e sua distribuição territorial. Caderno de Geografia, Belo Horizonte, v. 26, n. 46, p. 424-446, 2016.

VEIGA, B. S. Almanach Sulmineiro. Campanha: Typographia do monitor sulmineiro, 1874. 462p.

VEIGA, B. S. Almanach Sulmineiro. Campanha: Typographia do monitor sulmineiro, 1884. 679p.

WIRTH, J. O fiel da balança: Minas Gerais na federação brasileira, 1889 - 1937. Rio de Janeiro: Paz e Terra, 1982. 384p. 